\title{
Ecological speciation in the tropics: insights from comparative genetic studies in Amazonia
}

\author{
'Molecular Ecology Lab, School of Biological Sciences, Flinders University, Adelaide, SA, Australia \\ ${ }^{2}$ The Australian Museum, The Australian Museum Research Institute, Sydney, NSW, Australia \\ ${ }^{3}$ Departamento de Ciências Pesqueiras, Universidade Federal do Amazonas, Manaus, Brazil \\ ${ }^{4}$ National Museum of Marine Biology and Aquarium, Pintung, Taiwan \\ ${ }^{5}$ Division of Biological Sciences, University of Montana, Missoula, MT, USA
}

Luciano B. Beheregaray ${ }^{*}$, Georgina M. Cooke ${ }^{2}$, Ning L. Chao ${ }^{3,4}$ and Erin L. Landguth ${ }^{5}$

\section{Edited by:}

Toby Pennington, Royal Botanic Garden Edinburgh, UK

\section{Reviewed by:}

Octavio Salgueiro Paulo, Universidade de Lisboa, Portugal

James Edward Richardson, Royal Botanic Garden Edinburgh, UK

\section{${ }^{*}$ Correspondence:}

Luciano B. Beheregaray, Molecular Ecology Lab, School of Biological Sciences, Flinders University, Adelaide, SA 5001, Australia e-mail: luciano.beheregaray@ flinders.edu.au
Evolution creates and sustains biodiversity via adaptive changes in ecologically relevant traits. Ecologically mediated selection contributes to genetic divergence both in the presence or absence of geographic isolation between populations, and is considered an important driver of speciation. Indeed, the genetics of ecological speciation is becoming increasingly studied across a variety of taxa and environments. In this paper we review the literature of ecological speciation in the tropics. We report on low research productivity in tropical ecosystems and discuss reasons accounting for the rarity of studies. We argue for research programs that simultaneously address biogeographical and taxonomic questions in the tropics, while effectively assessing relationships between reproductive isolation and ecological divergence. To contribute toward this goal, we propose a new framework for ecological speciation that integrates information from phylogenetics, phylogeography, population genomics, and simulations in evolutionary landscape genetics (ELG). We introduce components of the framework, describe ELG simulations (a largely unexplored approach in ecological speciation), and discuss design and experimental feasibility within the context of tropical research. We then use published genetic datasets from populations of five codistributed Amazonian fish species to assess the performance of the framework in studies of tropical speciation. We suggest that these approaches can assist in distinguishing the relative contribution of natural selection from biogeographic history in the origin of biodiversity, even in complex ecosystems such as Amazonia. We also discuss on how to assess ecological speciation using ELG simulations that include selection. These integrative frameworks have considerable potential to enhance conservation management in biodiversity rich ecosystems and to complement historical biogeographic and evolutionary studies of tropical biotas.

Keywords: biogeography, adaptive divergence, evolutionary landscape genetics, phylogenetics, phylogeography, ecological genomics, tropical diversification, biodiversity conservation

\section{INTRODUCTION}

"Natural selection, as we shall hereafter see, is a power incessantly ready for action ..."

(Darwin, 1859)

Evolution creates and sustains biodiversity via adaptive changes in ecologically relevant traits. Understanding how organisms adapt and diversify have been topics of fundamental importance in biology for over 150 years (Losos et al., 2013). It is now realized that evolution reflects both historical and contemporary contingencies and is mediated by bidirectional interactions between ecological and evolutionary changes (Schoener, 2011; Losos et al., 2013). Thus, to understand adaptive changes and patterns of biological diversification it is often necessary to integrate information from both past (e.g., geomorphologic and paleoclimatic variation) and recent (e.g., natural selection) processes (Avise, 2000; Hoffmann and Sgro, 2011; Losos et al., 2013). Bridging macro and microevolutionary studies provides ways to clarify regional patterns of biological diversification and their underlying mechanisms of speciation. Here we focus on the contribution of studies that simultaneously assesses historical and ecologically driven signatures of population divergence to explain patterns of biodiversity in tropical ecosystems.

Speciation - the continuous process that gives rise to biological diversity, is often intimately associated to changes in phenotypes and to adaptation to the ecological environment (Darwin, 1859; Mayr, 1963; Dobzhansky, 1970). Natural selection contributes to ecological adaptation both in the presence or absence of geographic isolation between populations, and as a consequence, drives phenotypic diversification, population divergence, the evolution of reproductive isolation and the formation of new species (Endler, 1977, 1986; Schluter and Conte, 2009; Nosil, 2012). Ecologically mediated selection is considered an important driver of speciation (Schluter and Nagel, 1995; Schluter, 2001; Shafer and Wolf, 2013). Yet, ecological mechanisms driving reproductive isolation vary in space and time and can have different phenotypic and genetic signatures (Nosil, 2012), making it difficult to assess 
the role and the proportional contribution of natural selection in the origin of species. On the other hand, non-mechanistic spatial frameworks are generally easier to establish and to test, and as such have historically dominated the study of speciation. Such frameworks tend to focus on the geographic arrangement of populations undergoing reproductive isolation (e.g., allopatric, parapatric, or sympatric) instead of the processes driving the evolution of reproductive isolation. These studies have shown that allopatric speciation is common across taxonomic groups and biomes (Mayr, 1942; Coyne and Orr, 2004). They have also promoted the view that speciation primarily results from genetic drift due to geographic isolation over that of speciation via natural selection (Schluter, 2001; Via, 2001; Rundle and Nosil, 2005).

The increasing integration between molecular genetic approaches with theoretical and empirical ecological studies (both in the field and experimentally; Nosil, 2012; Shafer and Wolf, 2013) seen during the last 20 years has restored excitement about the role of ecology in speciation, returning to Darwin's (1859) original theory that divergence may be driven by adaptation rather than merely being a by-product of geographic isolation. The term 'ecological speciation' was coined during this period (Schluter, 1996) and can be defined as "the process by which barriers to gene flow evolve between populations as a result of ecologically based divergent selection between environments" (Nosil, 2012). During ecological speciation, populations occupying different biotic or abiotic environments or using different resources experience unique selection pressures that directly or indirectly result in reproductive isolation, even if the original populations remain in contact (Schluter, 2001). The historical foundations of ecological speciation are inextricably linked to the works of Darwin, Mayr, and Dobzhansky, which provide the reference with which 21 st century views of speciation should be contrasted (Harrison, 2012). As is often the case in evolutionary biology research, ecological speciation has not been free of criticism. These include discussions about the value of this terminology, its equivalency to parapatric and sympatric speciation, and the role of divergent natural selection in the speciation process (readers interested in contrasting views to those presented here should consult Sobel et al., 2010 and Harrison, 2012).

Ecological speciation can occur under several spatial scenarios from allopatry through to sympatry (Schluter, 2001; Coyne and Orr, 2004; Rundle and Nosil, 2005), with classical examples being parapatric (Endler, 1977; Sobel et al., 2010). Ecological divergence and reproductive isolation can evolve under a single or under multiple geographic scenarios (e.g., it could begin in allopatric and be completed in sympatric conditions, Rundle and Schluter, 2004). The geographic arrangement of populations is important because it affects the source of selection and rates of gene flow, but what is essential in ecological speciation is that the divergence be primarily driven by divergent selection (Nosil, 2012). Indeed, substantial population divergence and speciation is known to occur between ecologically dissimilar populations even in the face of ongoing gene flow between these (i.e., divergence-with-gene-flow; Smith et al., 1997; Beheregaray and Sunnucks, 2001; Schluter, 2001; Coyne and Orr, 2004; Schluter and Conte, 2009; Bernatchez et al., 2010; Cooke et al., 2012a; Sexton et al., 2014). Identifying these incipient ecological species represents an opportunity to investigate ongoing evolutionary processes in situations where adaptive divergence and reproductive isolation are associated (for a review see Orr and Smith, 1998). Allopatric ecological speciation might also be common in situations where ecological divergence is a stronger driver of reproductive isolation than genetic drift (Funk, 1998; Vines and Schluter, 2006).

Studying the role of ecology in the speciation process is a popular research area these days. Our Web of Science ${ }^{\circledR}$ search conducted in May 2014 indicated that 996 articles were published under the topic of "ecological speciation," with 862 of these being empirical studies. Interest in this research topic has grown exponentially in recent years, and so has the corresponding citation rate (Figure 1). For instance, 2013 has seen almost 200 publications and over 5,600 citations, compared to 60 articles and 1,600 citations in 2008. Interestingly, our evaluation shows that the majority of empirical studies (674 out of 862) used information from genetic datasets or genetic knowledge to improve pattern interpretation. Indeed, the genetics of ecological speciation is becoming increasingly studied across a variety of taxa and environments (Wolf et al., 2010; Nosil, 2012; Shafer and Wolf, 2013). As a result, speciation research has expanded beyond traditional boundaries, since genetic and genomic techniques now offer the means to disentangle the manifold (albeit complex) processes of drift from selection, across various evolutionary stages, environments and taxa (Moritz et al., 2000; Shafer and Wolf, 2013; Seehausen et al., 2014).

The initial aim of this paper is to examine the literature to assess the research interest about ecological speciation in the tropics, the region that encompasses the most-species rich ecosystems on Earth. Tropical rainforests and coral reefs house a disproportionally high number of species and, as a consequence, have become the focus of great attention of scientists and the general public (Primack, 2014). For instance, even though tropical rainforests occupy only $7 \%$ of the Earth's land area, they are estimated to contain most of the Earth's species (Corlett and Primack, 2010). Although several opinions, reviews, and a few meta-analyses have been published about speciation in the tropics (e.g., Haffer, 1997; Moritz et al., 2000; Wiens and Donoghue, 2004; Rull, 2008; Hoorn et al., 2010b; Salisbury et al., 2012; Bowen et al., 2013; Smith et al., 2014), to the best of our knowledge none have focused on ecological

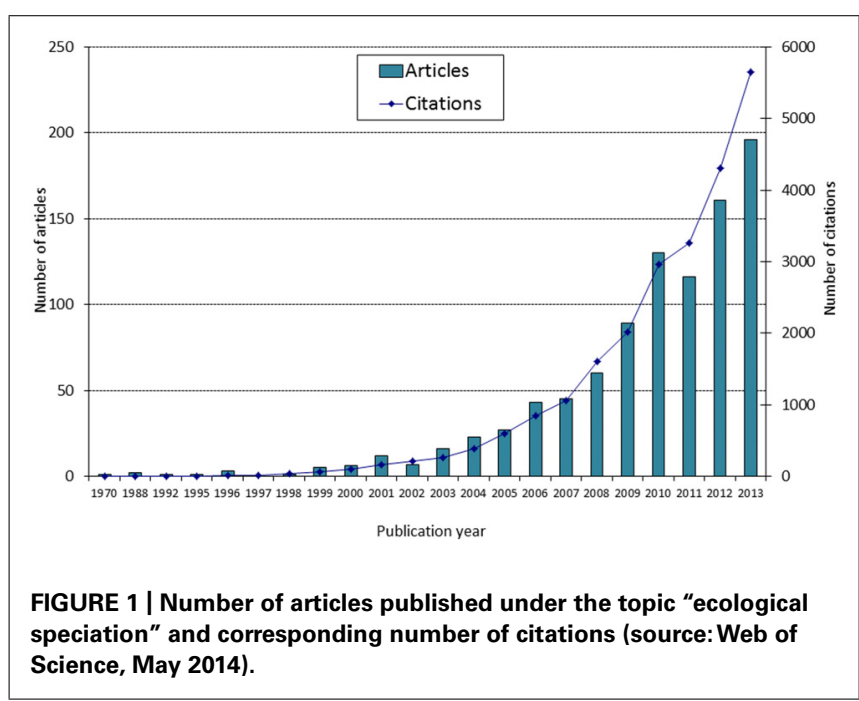


speciation. To address this shortcoming, we examine the empirical literature to identify analytical approaches that have been used to study ecological speciation in the tropics.

Motivated by a review about diversification of rainforest faunas (Moritz et al., 2000) and by our initial assessment of the literature, we further argue for analytical approaches that explore genomic (or genetic) datasets at the population level and thus bridge historical and ecological considerations in tropical speciation research. We perceive the need for a research program that simultaneously addresses large-scale biogeographical and taxonomic questions in the tropics, while effectively assessing finer-scale relationships between reproductive isolation and ecological divergence.

To contribute toward this goal, we propose a framework for ecological speciation research that integrates information from evolutionary landscape genetics (ELG), genome scans, population genetics, phylogeography, and phylogenetics. We then use published population-level genetic datasets from five codistributed and taxonomically diverse Amazonian fish species (Cooke etal., 2012a,b,c,d, 2014) to illustrate the performance of the framework in studies of tropical speciation. Specifically, these studies examine the accumulation of population and lineage diversity in these fish groups within the context of geomorphological history, tributary arrangement, and divergent natural selection putatively associated with hydrochemical ecotones (i.e., at the interface of major rivers with different 'water colors'). Although these lineages show different biogeographic and evolutionary histories, striking commonalities exist in the way that population genetic divergence and incipient speciation appear to be ecologically induced and spatially influenced by ecotones.

We suggest that this framework can assist in distinguishing the relative contribution of natural selection from biogeographic history in the origin and maintenance of biodiversity, even in a complex and understudied tropical ecosystem such as Amazonia. In addition, we show that it is feasible to frame ecological speciation in a spatially explicit ELG context that includes selection. We also discuss recent developments in environmental mapping, simulations and population genomics that allow clarification of population divergence across selection gradients.

\section{WHY IS THE RESEARCH EFFORT IN ECOLOGICAL SPECIATION SO LOW IN TROPICAL ECOSYSTEMS?}

Our assessment of empirical research productivity in ecological speciation shows that the tropics have been largely left behind compared to other ecosystems. Only 51 publications $(5.2 \%)$ out of the 996 previously identified articles (Figure 1) dealt with tropical species, and only 40 of those could be classified as empirical studies. Although our searches might have missed relevant studies that did not use the words "tropical" or "tropic(s)" in the abstracts, keywords, or titles, our inspection of the literature indicates that research effort in ecological speciation is indeed largely biased toward temperate regions. This conclusion is consistent with the empirical literature reviewed in a recently published book on ecological speciation (Nosil, 2012), with a review of the topic (Rundle and Nosil, 2005) and with several syntheses about tropical diversification (Moritz et al., 2000; Rull, 2008; Bowen et al., 2013).
Research trends in tropical ecological speciation were collected by inspecting the 40 recovered empirical articles for key selected categories. In terms of biological realm, most publications focused on terrestrial $(65 \%)$, rather than marine $(20 \%)$, or freshwater (15\%) organisms. Terrestrial plants and terrestrial invertebrates were the best represented taxonomic groups (each with $27 \%$ of total articles), followed by fishes $(17 \%)$, aquatic invertebrates (15\%), birds (12\%), herpetofauna $(10 \%)$, and mammals $(3 \%)$. Comparisons involving two or more species (65\%) were more common than intraspecific surveys (35\%). Interestingly, $45 \%$ of studies included comparisons across habitat gradients, and 35\% of the 40 articles assessed patterns of gene flow. In terms of the main approaches used to generate and analyze data (Figure 2), a large proportion of studies used information from molecular phylogenetics (63\%), phylogeography (50\%) and morphology $(42 \%)$. To our surprise, only few surveys of population genetic structure were conducted in the topics (27\% of the total), with a handful of those also incorporating information from genome scans of selection $(10 \%)$ or from landscape genetics $(7.5 \%)$. As expected for any integrative field of research, ecological speciation was usually assessed by combining two or more approaches $(80 \%$ of articles). Most combinations (83\%) included phylogenetic or phylogeographic datasets, exemplifying the reliance of the field on molecular genealogical information.

What are the reasons for the rarity of ecological speciation research in tropical regions? First of all, basic taxonomic, ecological and distributional data are usually either inadequate or simply non-existent for most tropical biotas. Such information is needed to identify ecological 'opportunities' for speciation but is currently limited and hard to collect in the tropics compared to temperate regions because of the tropics' inherently high levels of biodiversity, endemism and remoteness. In addition, tropical ecosystems are typically found in developing countries, where essential resources (e.g., research funding, in situ capacity and accessible cataloged bio inventories) are the scarcest. The latter is consistent with the positive correlation found in another review (Beheregaray, 2008) between global research productivity of population-level genealogical surveys with country's wealth.

The low number of studies on ecological speciation might also be related to a historic research bias toward clarifying speciation timing and rates of diversification in the tropics. Many studies

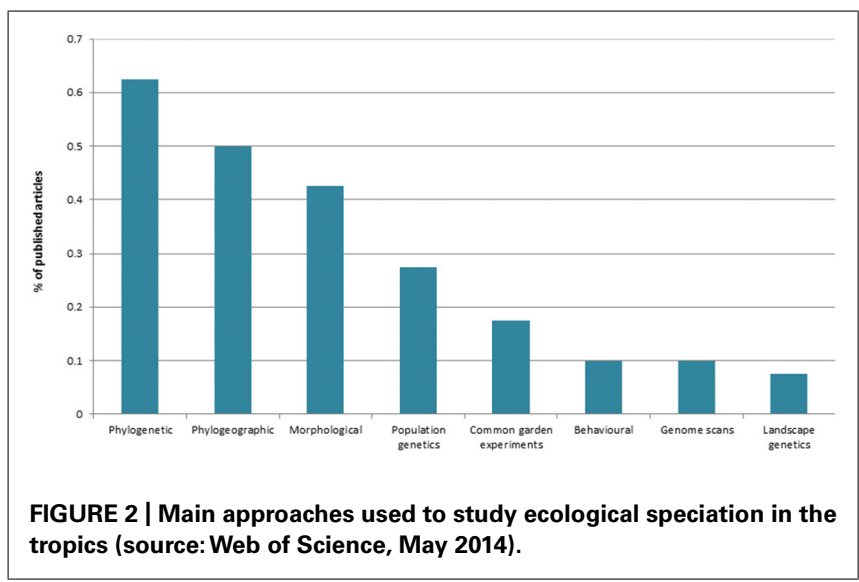


of speciation have used molecular phylogenies (e.g., Figure 2) to clarify temporal and spatial patterns of diversification in tropical ecosystems. These surveys and meta-analyses have invariably compared lineages at or above the species level and framed pattern interpretation within historical biogeographic and macroevolutionary contexts. They have contributed substantially to our understanding of tropical diversity - such as improving the quality of the contentious debate about Tertiary versus Quaternary speciation timing (Pennington et al., 2004; Rull, 2008; Hoorn et al., 2010b, 2011; Antonelli and Sanmartín, 2011) and clarifying general patterns of diversity and diversification (e.g., for birds, Salisbury et al., 2012; plants, Richardson et al., 2001; Hughes et al., 2013; and mammals, Rolland et al., 2014). However, we believe they have also created a paradigm about tropical speciation that often ignores population-level information and the roles of ecology and natural selection in the origin of species. Any biogeographic scenario, recent or historical, begins with population differentiation, a process underpinned by changes in the physical and biotic environments of populations (Darwin, 1859; Avise, 2000). Ecological considerations at the scale of demes are therefore relevant to understanding not only underpinnings of population divergence and incipient speciation but also to inform large-scale biogeographical patterns (Wiens and Donoghue, 2004). Indeed, there is mounting evidence from multiple taxa and ecosystems suggesting that divergent natural selection might be an important driver of biodiversity (Schluter, 2000; Coyne and Orr, 2004; Rundle and Nosil, 2005; Schluter and Conte, 2009), including the tropics (Smith et al., 1997, 2001; Schneider et al., 1999; GarciaParis et al., 2000; Ogden and Thorpe, 2002; Lopez-Fernandez et al., 2010; Cooke et al., 2012a,b,c,d, 2014).

\section{AN INTEGRATED GENETIC-BASED FRAMEWORK FOR STUDYING ECOLOGICAL SPECIATION IN THE TROPICS}

We now describe a framework to study ecological speciation in the tropics that integrates genomic (or genetic) data from populations with simulation modeling specific for ELG (summarized in Box I; Figure 3). Although the primary impetus is to assess the role of ecology as a driver of biodiversity, this type of research also generates valuable information for several data-deficient areas in tropical research. These include improvements of biological inventory databases and taxonomy, the discovery and delineation of cryptic species, selection gradients, ecotones and regional hotspots for conservation management, and the clarification of speciation timing, patterns of connectivity and metapopulation structure.

Below we introduce the main components of the framework and discuss design and experimental feasibility within the context of tropical research. We also provide a more detailed description of simulations and ELG (two largely unexplored approaches in ecological speciation) and their expected contributions. This is followed by a performance assessment of the proposed research framework based on published studies of population diversification and ecological speciation of Amazonian fishes.

\section{SAMPLING STRATEGIES AND PHENOTYPIC INFORMATION}

Beginning with sampling a particular study system, the framework allows for both single-taxon studies and for comparative analyses

\section{BOX I| Rationale.}

The emphasis of the framework is about assessing gene flow among populations (or preferably, among adaptive phenotypes) distributed across heterogeneous environments or ecotones while controlling for spatial genetic autocorrelation and vicariant history. In this scenario, evidence for ecological speciation is obtained if a positive correlation is found between genetic differentiation and environmental (or phenotypic) divergence, after the effects of geographic distance (Shafer and Wolf, 2013; Sexton etal., 2014) and historical biogeography between populations are accounted for. This is considered evidence because ecologically divergent selection across environments can reduce gene flow between populations and in this way drive local adaptation and population divergence (Schluter, 2000; Räsänen and Hendry, 2008; Nosil, 2012). Notwithstanding the focus on population genetics, the framework also integrates genealogical information from phylogenetics and phylogeography to disentangle ecological divergence from vicariant biogeographic history. This distinction is needed because ecological speciation usually requires a study system in which the existence of an allopatric phase is very unlikely in the context of evolutionary history (Endler, 1982; Coyne, 2007; Nosil, 2008). In an additional conceptual and analytical step, we synergistically combine the outcomes of above-mentioned empirical analyses of gene flow and population diversification with spatially explicit simulations in evolutionary landscape genetics, ELG (Landguth et al., 2012, 2014). These ELG simulations can be used to statistically assess inferred scenarios of environmentally induced population divergence. They can also shed light on the role of landscape structure and individual based organism response to landscape structure in the evolution of reproductive isolation (Box II). Although this framework was conceived to assess ecological speciation in the tropics, it can be applied to other ecosystems and to most sexually reproducing species. This is particularly true for biotas in temperate regions for which a priori information about traits subject to divergent selection is more abundant and for which better logistics allow greater experimental tractability (Nosil, 2012) compared to biotas from tropical regions.

that use population samples from codistributed species. Although population-level sampling and data collection for codistributed species can be logistically intricate and expensive, comparative studies are often more powerful and rewarding than single taxon surveys. Such studies allow for the identification of biogeographic histories that are shared among biotas (Avise, 1992; Bernatchez and Wilson, 1998) and regions that promote rapid adaptive evolution, have high concentrations of historically isolated populations, or both (Davis et al., 2008; Carnaval et al., 2009). In this case, sampling species across a range of mobility and life histories provides a powerful strategy to make generalizations about the effects of landscape history and environmental structure on gene flow (e.g., Galarza et al., 2009). Our proposal to integrate diverse empirical and simulated approaches (Figure 3 ) is valuable for comparative surveys because the applicability of individual approaches for assessing ecological speciation scenarios is expected to vary among groups of organisms (Nosil, 2012).

Natural selection works on phenotype, and the connections between selection on ordinary phenotypic traits and reproductive isolation are often strong and straightforward (Schluter, 2001). On the other hand, the complexity of both the environmental variation and the genetic basis of adaptive phenotypes hamper our ability to use genetic data to map adaptive variation over 


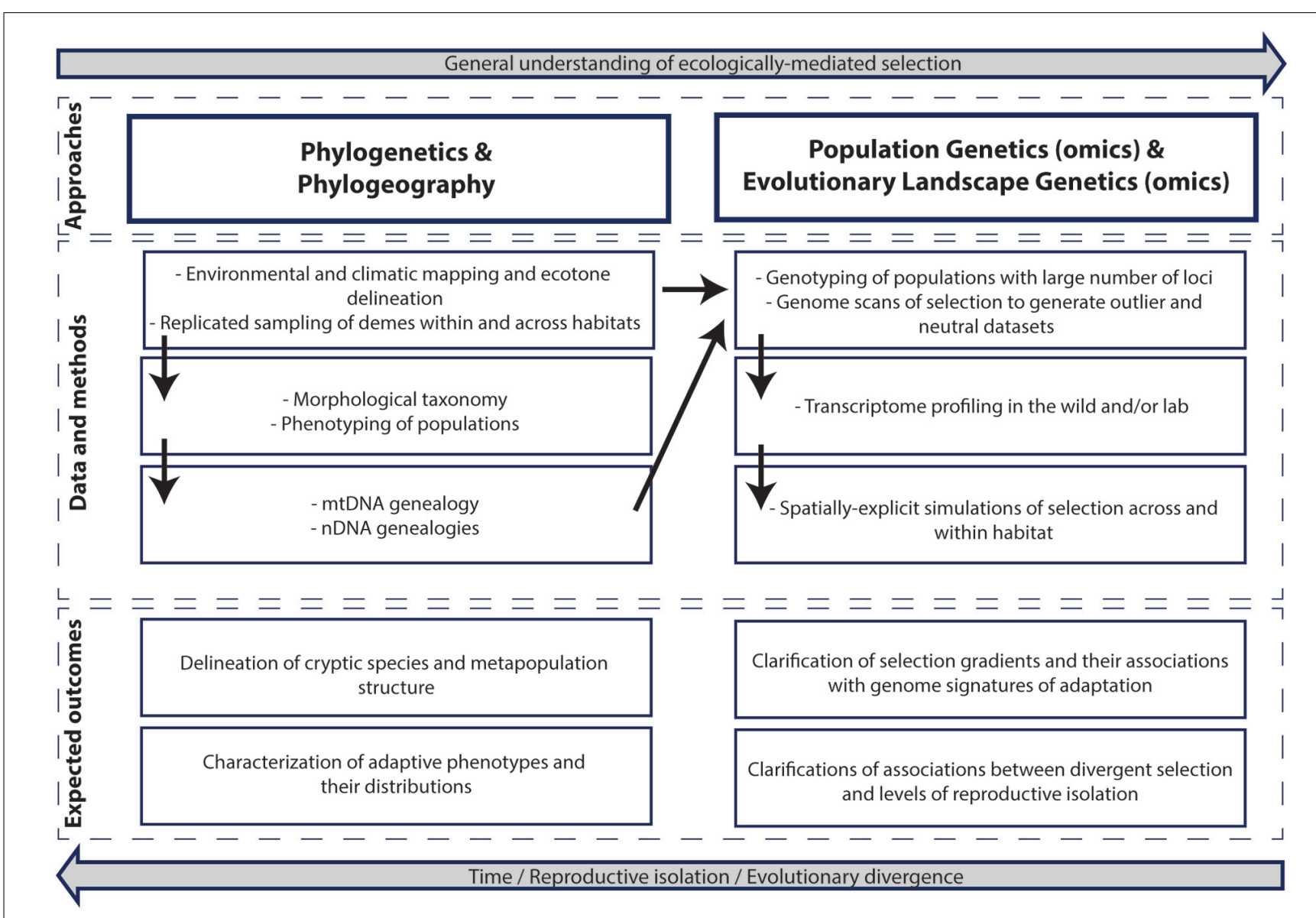

FIGURE 3 | A conceptual and analytical framework to study ecological speciation in the tropics based on genetic, genomic and non-genetic data and simulation modeling (see text for details). The upper boxes show approaches that when integrated can improve understanding of ecologically mediated selection. The middle boxes show the main methods and types of data, whereas the bottom boxes show expected outcomes. The diagram exemplifies a single-taxon study but it can also be extended to comparative surveys. This framework can be applied to other ecosystems. the landscape (Lowry, 2010; Schoville et al., 2012). The spatial delineation of ecologically relevant phenotypes (i.e., adaptive phenotypes; Figure 3 ) or of traits related to reproductive isolation can be fundamentally important to generate hypotheses about divergence across environmental gradients and to inform sampling strategies. In cases where a priori information is available about the distribution of phenotypically divergent ecotypes within species or between closely related lineages (e.g., Bernatchez et al., 2010) it might be prudent to invest in replicated population sampling across geographically separate but similar environments (Smith et al., 1997). Here, evidence for independently repeated genetic divergence (neutral or adaptive) in divergent phenotypes correlated with similar environmental gradients is strong evidence for selection (Bernatchez et al., 2010; Rosenblum and Harmon, 2011).

Regardless of whether a single or multiple species are being targeted, intensive sampling (both in number of individuals per deme and in number of demes) is required to ensure rigorous statistical analyses. Within lineages, sampling should be hierarchical to enable analyses of spatial dependence: the design should be spatially nested regarding dispersal potential to capture the degree of autocorrelated genetic data (due to daily dispersal) and the environmental-species relationships (due to beyond natal dispersal; Manel et al., 2010).

The rigorous sampling regime proposed here contrasts remarkably with the sparse sampling strategies generally used in phylogeographic and phylogenetic studies of tropical biotas (Beheregaray, 2008; Rull, 2008; Antonelli and Sanmartín, 2011). Although intensive population sampling might be seen prohibitive for some projects, efforts to document biodiversity in the tropics have increased and become more integrated in recent years (Janzen etal., 2009). Consistent with this view, responsible collection of specimens and associated data and openly sharing of this knowledge have been advocated (Rocha et al., 2014). Similarly, the field of biogeography seems to be experiencing a renaissance for inter-disciplinary research associated in part with the realized and potential impact of rapid data accumulation for poorly studied regions (Dawson et al., 2013). Altogether, these and other developments (e.g., the recently created open access journal Scientific Data) should contribute to improving and accelerating initiatives supporting bioinventory collections and population sampling in the 


\section{BOX II | General aims (left) and questions that can be addressed with ELG simulations.}

Theoretical: Integrate landscape genetics framework into understanding events driving reproductive isolation

Analytical: Validating outlier approaches in detecting selection associated with the evolution of hybrid incompatibility.

Empirical: Testing evidence of ecological speciation in datasets
How do spatial selection gradients with individual-based movement strategies influence the emergence of reproductively isolated genotypes?

How do heterogeneous landscapes with various spatial selection gradient configurations and individual-based movement strategies influence the emergence and evolution of reproductively isolated genotypes?

How are hybrid zones shaped by individual-based movement strategies, heterogeneous landscapes, and spatial selection gradients?

How well can standard outlier detection methods detect loci that are under endogenous (i.e., genetic incompatibilities) or exogenous (i.e., environment) selection?

What are the interactions between endogenous and exogenous selection in the landscape genetics framework?

What assumptions and parameters lead to reproductive isolation in an empirical system?

How sensitive are the assumptions to changes in selection strength, dispersal capability, and/or changing landscapes? tropics. Population genetic surveys should tag along to ensure that tissue samples for DNA analysis (and in some cases for transcriptomics, Figure 3), are collected together with voucher specimens and other key associated data such as phenotypic information.

\section{LANDSCAPE MAPPING}

Landscape (or riverscape or seascape) mapping is an important step that should be carried out in parallel with sampling design. A landscape is an area that is heterogeneous with regard to at least one variable of interest (Turner et al., 2001). A landscape with low permeability can decrease gene flow, while increasing genetic drift and population structure. The purpose of incorporating such information is to identify environmental and climatic gradients that might be impacting on both the structural and functional habitats of study species. This should improve the delineation of ecotones or habitat transition areas and thus inform on the most appropriate sampling design. It also creates scenarios to anchor empirical analyses of gene flow and simulations in ELG (discussed below). Mapping can be done based on data collected in the field or using existing GIS datasets that contain summary statistics for variables of interest, such as climate, landcover, structural habitat, topography, disturbance, and ecosystem productivity. For example, climate data can be gathered from WorldClim (Schoville et al., 2012) and Microclim (Kearney et al., 2014). Looking ahead, the increase availability of rich environmental and climatic data is expected to enable sophisticated functional analyses that can potentially be used in ecological speciation research. For instance, mechanistic niche models or probability of occurrence maps that identify functional traits that limit distributions (e.g., physiological responses and constraints) provide a view of the fundamental niche that can then be mapped to the landscape (Kearney and Porter, 2009). These traits can be allowed to evolve (e.g., by incorporating selection and heritability) to explore the potential impact of evolution and to predict adaptive dynamics and distribution shifts (Kearney and Porter, 2009; Hoffmann and Sgro, 2011). Rich ecological datasets that include measures of resource availability and biotic interactions are also expected to positively impact ELG by providing an opportunity to test whether specific ecological factors drive adaptive genetic variation (Schoville et al., 2012).

\section{PHYLOGENETICS AND PHYLOGEOGRAPHY}

The integration of molecular genealogical information from phylogenetic and phylogeographic analyses into the framework is a prerequisite for subsequent analyses of intraspecific (i.e., within lineages) gene flow. Two main reasons account for this requirement. First, these analyses enable the discovery and spatial delineation of historically isolated lineages and hidden biodiversity, such as evolutionarily significant units (ESUs) and cryptic species. Levels of species richness and morphologically cryptic biodiversity have been grossly underdocumented in assessments of tropical biodiversity (e.g., Parra-Olea and Wake, 2001; Cooke et al., 2012d; Funk et al., 2012) because these rarely employ thorough morphology-based analyses, intensive population sampling and DNA-based methods (Beheregaray and Caccone, 2007; Beheregaray, 2008). For instance, our comparative research program on the evolution of Amazonian fishes focused on species suspected to be represented by a single evolutionary lineage across the range of each taxon. We sampled populations from four nominal taxa (i.e., species) from a project on upper reaches of the Negro river and from five nominal taxa for the water color project described below. After performing genealogical and population genetic analyses it became evident that we were actually working with, respectively, a minimum of eight (e.g., Cooke et al., 2009; Sistrom et al., 2009; Piggott et al., 2011) and eleven (e.g., Cooke et al., 2012a,b,c,d, 2014) ancient cryptic species in each project. Notwithstanding the value of molecular data, we recognize that 
morphology-based taxonomy has a central and unrivaled position in biodiversity research (Schlick-Steiner et al., 2007) and advocate for resource investment toward traditional taxonomy and museum collections to ensure that newly reported cryptic species will be properly cataloged and described following discovery.

The second reason for integrating molecular genealogical studies is that they add an essential component to the understanding of patterns of population structure and levels of reproductive isolation: time. Temporal changes in the physical and biotic environment of a population lead to demographic variations that are correlated with the structure of population genealogies (Avise, 2000). Phylogeographic studies, when integrated with information from historical disciplines of Earth sciences, can potentially describe the chronology of demographic variation and reproductive isolation of population units (Avise et al., 1998; Hewitt, 2001). As such, they can disentangle scenarios of relatively recent divergence due to ecology - the setting targeted by studies of ecological speciation, from patterns of allopatric divergence due to vicariant biogeographic history. Phylogeographic analyses can also address questions about the species divergence process that cannot be addressed without genealogical data. These include clarifying how evolutionary divergence proceeds in the context of colonization and ecological opportunity (Beheregaray et al., 2004), and how repeated distributional shifts may have constrained diversification to taxa in which reproductive isolation apparently evolves very quickly (Carstens and Knowles, 2006).

\section{POPULATION STRUCTURE, GENE FLOW AND GENOME SCANS OF SELECTION}

In this step, DNA markers are used to genotype individuals across heterogeneous environments with the aim of clarifying patterns of gene flow and identifying the spatial locations of genetic discontinuities (i.e., population boundaries). This is a key step in the framework that should be done at the metapopulation level after historical diversification has been accounted for (as above). The expectation is that during ecological speciation, ecological or environmental distance (analogous to geographic distance), reduces homogenizing gene flow and correlates to genetic population differentiation. These patterns are now considered common in nature and usually referred to as isolation-by-ecology (Shafer and Wolf, 2013), or isolation-by-environment (Sexton et al., 2014). Evidence indicates that adaptive divergence between selective environments constrains gene flow through selection against either immigrants or hybrids (Schluter, 2000; Räsänen and Hendry, 2008). Similar to what happens in allopatric and parapatric speciation, ecologically induced population differentiation might not necessarily produce complete reproductive isolation or new species (Hendry, 2009; Nosil, 2012).

Although isolation-by-ecology can be detected with relatively small neutral molecular datasets such as microsatellites and AFLPs (Shafer and Wolf, 2013; see below for examples), next-generationsequencing (NGS) methods now offer the possibility of identifying and typing 1000s of genetic markers (i.e., SNPs) for population genomic analysis. These included genotyping-by-sequencing methods that enable screening SNPs throughout the genome of non-model species in a relatively inexpensive manner (Narum et al., 2013). Using a large number of genetic markers is important in ecological speciation research. These markers can clarify evolutionary relationships between populations, ecotypes and lineages, while improving delineation of barriers to gene flow, selection gradients and patterns of isolation-by-ecology caused by demographic factors. Simultaneously, these large datasets can be used to identify genomic regions (or specific loci) that show evidence of divergent selection (Luikart et al., 2003; Seehausen et al., 2014). In population genomics, the latter step is often done using genome scans that compare allelic variation at markers spread throughout the genome in many individuals from ecologically different populations or species. During genome scans of selection, markers that potentially carry the signature of natural selection (i.e., 'outlier' loci used to characterize population adaptations) will be distinguished from neutral markers (i.e., markers used to infer population parameters and phylogeography) because they exhibit exceptionally high levels of differentiation (Luikart et al., 2003; Beaumont, 2005). The premise of the method is that drift, inbreeding and gene flow usually have genome wide effects, whereas selection leaves signatures only at those loci that are adaptive to a particular scenario (Luikart et al., 2003; Seehausen et al., 2014). As such, differentiation will accumulate in regions under selection, whereas in other regions, genetic drift will require longer periods of time to accumulate ( $\mathrm{Wu}, 2001$; Nosil et al., 2009). By extension, sympatric or parapatric populations evolving in the presence of gene flow are predicted to show greater heterogeneity across the genome than spatially isolated populations (Wu, 2001; Nosil et al., 2009; but see Renaut et al., 2013).

\section{SIMULATION MODELING FOR EVOLUTIONARY LANDSCAPE GENETICS}

In this section, we provide an introduction about simulations and landscape genetics (for a review see, Landguth et al., 2014) and list general questions that can be addressed with this type of approach (Box II). Simulations have provided many important findings in various disciplines (e.g., Grimm and Railsback, 2005), and are increasingly accepted by empiricists (Jeltsch et al., 2013). The quasi-experimental framework of simulation models offers several important benefits for scientific research. For example, the ability to repeat simulations of a system with varying parameters (sensitivity analysis) allows researchers to assess how much confidence we can put in the conclusions derived from simulations and to predict how a system or its behavior will change if certain processes are altered. With empirical data, the range of parameter values and assumptions that can be tested is usually much more limited, potentially leading to weaker or more uncertain inferences. Simulations can also mimic perfect sampling conditions, which can lead to stronger inferences (see review in Balkenhol and Fortin, 2014). In sum, simulation modeling can be used to predict and explain, guide sampling and data collection, illuminate core dynamics of a system, discover new questions, bound outcomes to plausible ranges, quantify uncertainties, and train students and practitioners (Epstein, 2007).

Simulations have been used in population and landscape genetics for many years, and the availability of software for simulating genetic data is increasing steadily (reviewed in Hoban et al., 2012; Hoban, 2014). However, there are important differences between 
ELG simulations and 'classic' population genetic simulations. First, many genetic simulation approaches generate genetic data (i.e., summary statistics) only at the population-level. In contrast, many ELG approaches produce genetic data for every individual (even if these are grouped into populations), and thus rely on individualbased models (IBMs). IBMs are classes of computational models for simulating the actions and interactions of autonomous individuals. Individuals can differ in their attributes (e.g., males vs. females) and these attributes influence their actions (e.g., different dispersal for males vs. females), as well as their reactions toward each other (e.g., mating strategies) or to other simulation settings (e.g., varying propensity to cross simulated barriers for males vs. females).

A second major characteristic of ELG simulations is the fact they are always based on spatially explicit models. These models are defined by placing individuals or groups of individuals (i.e., populations) on 1- or 2-dimensional regular lattices, or in irregular $\left(\mathrm{x}^{-}, \mathrm{y}^{-}\right)$coordinate space. Specific rules in the model then define how individuals move and interact across space, for example by defining the distances they can move away from their birth location, or the distance within which they can find a mating partner. Population genetic simulations are often also spatially explicit (e.g., Balloux, 2001), but while simulating population genetic data without space is possible, this is not the case for ELG simulations. In addition to space, another vital feature of ELG simulations is the direct incorporation of environmental heterogeneity into the underlying model. This usually requires a spatial representation of the environment that individuals are placed in. Importantly, this environment is spatially variable (i.e., non-homogeneous) in space, and potentially also in time, and it directly affects some or all of the essential processes included in the model. Thus, the rules that govern the actions and reactions of simulated individuals not only depend on pure space, but also on the user-defined environmental heterogeneity included in the model. This is the key distinguishing feature between population genetic and landscape genetic simulation modeling.

The ELG simulation modeling implemented in our ecological speciation framework includes an additional component: it specifically integrates landscape genetics and evolutionary genetics, focusing on how space and selection impacts on the evolution of reproductive isolation (speciation). For example, selection can be controlled via fitness landscape surfaces (Wright, 1932; Gavrilets, 2004) that determine the genotype-dependent viability of offspring in a spatially explicit setting. Let us consider a single bi-allelic locus model in which three relative fitness surfaces are specified for the three genotypes (AA, Aa, and aa). Selection is then implemented through differential survival of offspring as a function of the relative fitness of its genotype [e.g., determined in 'water color' in our Amazonian study (Cooke et al., 2014); see below] at the location on that surface where the dispersing individual settles. Then, through ELG simulations (e.g., Landguth et al., 2012), one can explore modeling of natural selection in landscape genetics with individual organism dynamics. Through sensitivity and uncertainty analysis, a factorial study design can be used with a range of species-specific dispersal strategies (controlling for gene flow) across landscape resistance scenarios. In addition, a range of genetic parameters and exogenous selection (arising from the environment) as well as endogenous selection (arising from genetic incompatibilities) can be explored while tracking the evolution of reproductive isolation (e.g., Cooke et al., 2014). Note that, when attempting to understand endogenous selection in spatial settings, fitness is determined by epistatic interactions, in form of the wellknown Dobzhansky-Muller model (Dobzhansky, 1937; Muller, 1942; e.g., Eppstein etal., 2009). Thus, extensions to multiloci selection models must be considered for addressing these questions.

\section{FRAMEWORK TESTING: COMPARATIVE ANALYSIS OF PHYLOGEOGRAPHY AND ECOLOGICAL SPECIATION IN AMAZONIAN FISHES}

Here, we provide a number of examples from our published work (Cooke et al., 2012a,b,c,d, 2014) that illustrate how integrating population genetics, genome scans of selection, ELG and sequenced-based phylogeographic and phylogenetic methods can be used to assess the relative influence of environmental gradients and biogeographic history in shaping Amazonian fish biodiversity. The studies used a thorough sampling design and amassed 905 individuals from 48 putative populations of five taxonomically diverse and ecologically distinct fish species endemic to Amazonia (Figure 4). These included freshwater representatives of marine-derived lineages from two orders; a tetraodontiform (the puffer Colomesus asellus) and a perciform (the croaker Plagioscion squamosissimus) and ancient freshwater lineages representing three Gondwana-relict orders; a characiform (the characin Triportheus albus), a siluriform (the catfish Centromochlus existimatus) and a gymnotiform (the electric fish Steatogenys elegans). Nuclear and mitochondrial DNA (mtDNA) sequences were used for genealogical analyses and AFLP datasets were used for analyses of gene flow and genome scans. Readers interested about species-specific datasets, analytical methods, and detailed biogeographic reconstructions should refer to our five publications (Cooke et al., 2012a,b,c,d, 2014).

The five species are largely codistributed, yet results indicate they have very different evolutionary histories. Phylogenetic analyses unexpectedly revealed five cryptic species within the catfish $C$. existimatus and two fully sympatric cryptic species within the electric fish S. elegans (Figure 5). Molecular dating indicates that these lineages all diverged during middle to late Miocene (Figure 6). In contrast, there was no evidence for cryptic species within the marine-derived taxa or within $T$. albus (Figures 5 and 6). Despite these differences, however, several congruous patterns that may actually reflect general forces shaping freshwater biodiversity in Amazonia were detected. Below we introduce the study region and summarize key comparative findings about inferred spatial arrangements of neutral and putatively adaptive genetic diversity. These are discussed within the contexts of geomorphological history of Amazonia and divergent selection.

\section{STUDY SYSTEM}

The Amazonian aquatic environment sustains dramatic hydrochemical and ecological gradients that impose physiological 


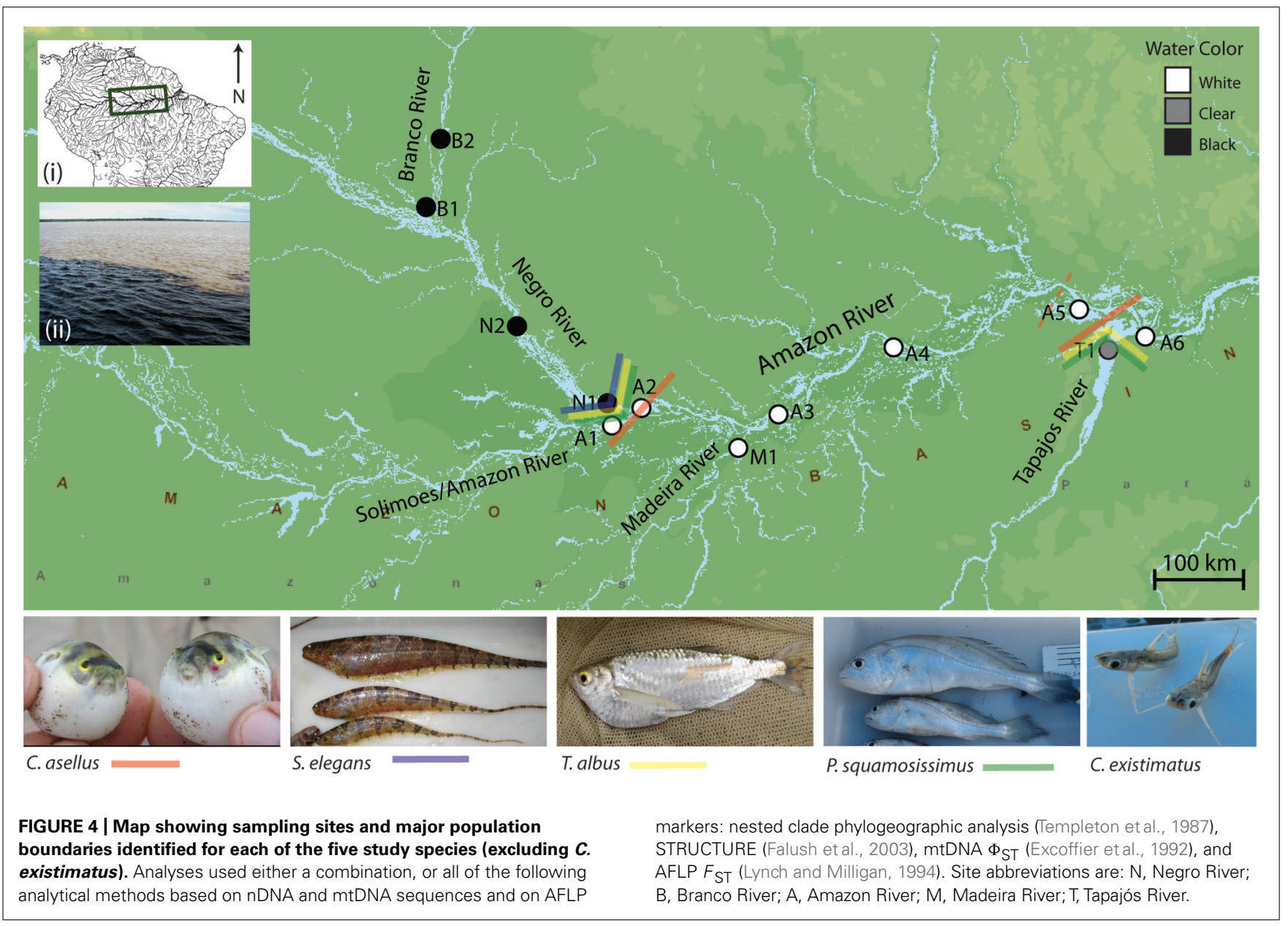

constraints upon its aquatic communities (Junk et al., 1983; Henderson and Crampton, 1997; Rodriguez and Lewis, 1997; Saint-Paul et al., 2000; Petry et al., 2003). These aquatic conditions have been grouped into three water types or 'colors' and are differentiated largely by sediment composition, geochemistry and optical characteristics (Sioli, 1984): (i) white water, which has an Andean origin, is turbid in nature and is characterized by large amounts of dissolved solids and a neutral pH; (ii) clear water, which is comparatively transparent and contains low content of dissolved solids and a neutral pH; and (iii) black water, which is transparent yet stained by tannins and humic acids leached from vegetation and has low $\mathrm{pH}(\mathrm{pH} \sim 5$ or lower). Both clear and black water differ from white water in that they are craton born, draining the Brazilian and Guyana shields, respectively (Hoorn et al., 2010a). As a result, their sediment composition and channel formation are different from the fast-turbid Andean white waters. Major ecological gradients have been shown to generate biodiversity via divergent natural selection elsewhere (Endler, 1973; Smith et al., 1997, 2001). This led to the prediction that major differences in water color between rivers of the Amazon Basin provide ecological opportunities for natural selection to drive genetic divergence between populations of aquatic organisms.

The study system within the Amazon Basin consists of the five major rivers representing white, black and clear waters: the Amazon (white), Madeira (white), Branco (seasonally black), Negro (black), and Tapajós (clear; Figure 4). The study area encompasses two putatively strong selection gradients or ecotones: where the black waters of the Negro River meets the white waters of the Amazon River, and where the clear waters of the Tapajós River meets the white waters of the Amazon River. Additionally, the transect allows testing for genetic structure geographically associated with river confluence. That is because two controls in which rivers of the same water color meet were included: the confluence of the black waters of the Branco and Negro Rivers and the confluence of the white waters of the Madeira and Amazon Rivers (Figure 4).

\section{COMPARATIVE PATTERNS}

Despite differences in ecology and phylogenetic history, strong evidence indicates that the biogeographic and ecological contexts of the Amazon Basin have promoted largely congruent finescale phylogeographic and population-level structuring. From a genealogical perspective, all species showed strong signals of demographic expansion and in every case the timing of these occurred well within the Quaternary period, with the exception of $C$. asellus whose expansion began $\sim 0.5 \mathrm{Ma}$ earlier (Table 1). 

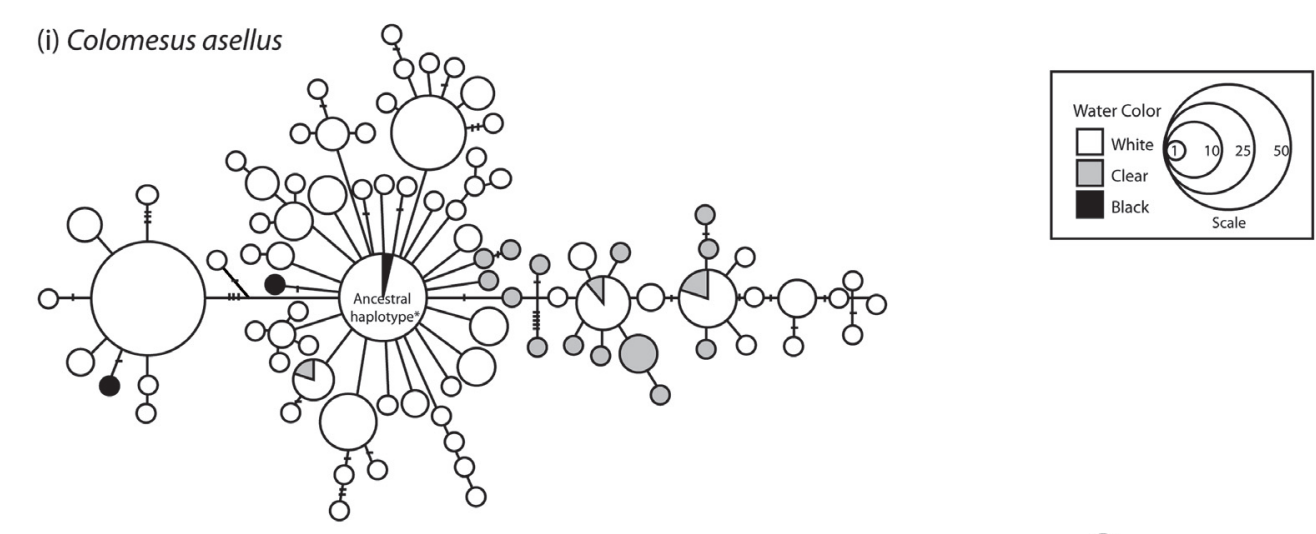

(ii) Plagioscion squamosissimus

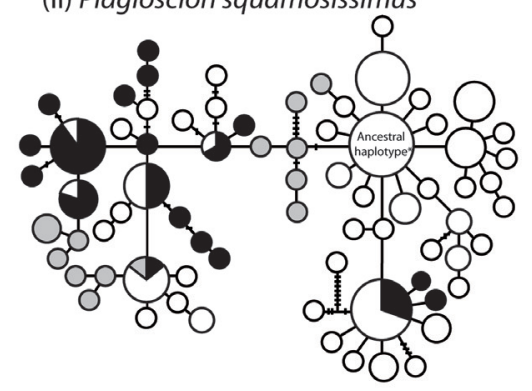

(iii) Triportheus albus

(iv) Steatogenys elegans (Species complex)

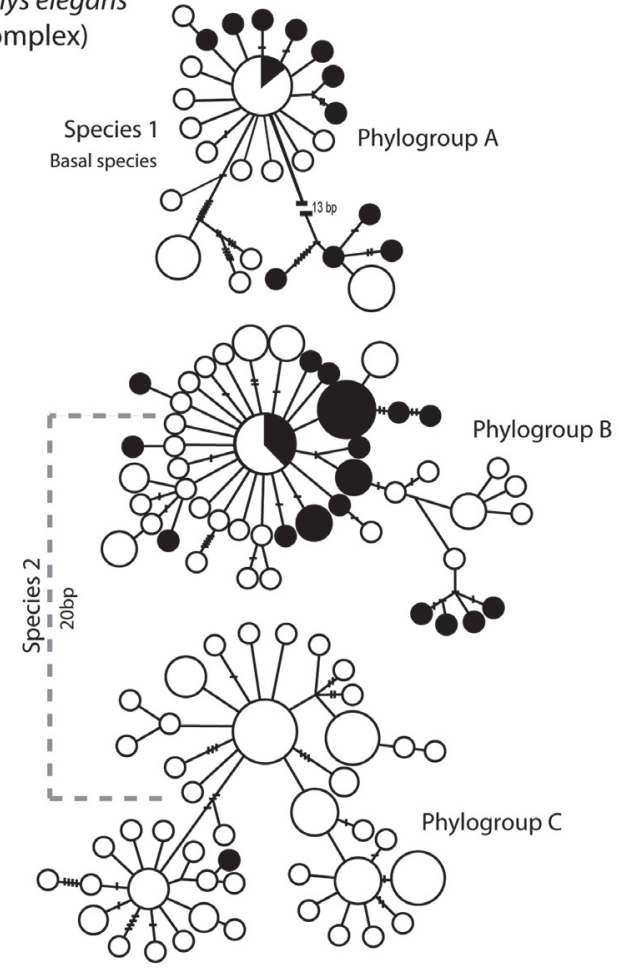

(v) Centromochlus existimatus

(Species complex)
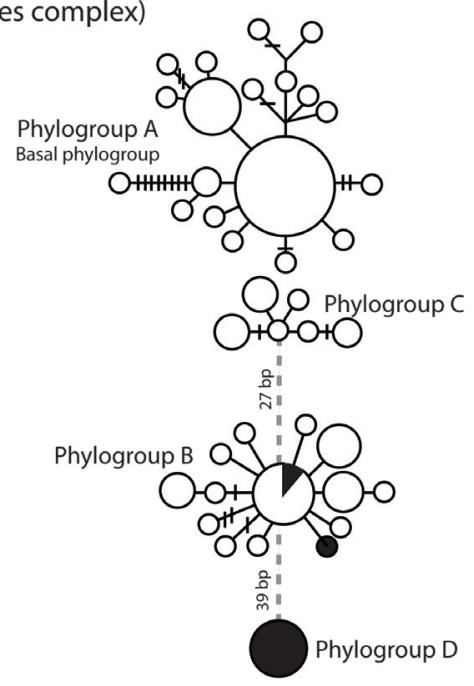

Phylogroup $\mathrm{E}$ $\mathrm{O}-\mathrm{O}$

FIGURE 5 | Genealogical relationships for each species and species complex based on mtDNA ATPase 6 and 8 sequences.

Relationships among haplotypes were estimated following Templeton etal. (1992). Each circle denotes a unique haplotype and the area of the circle is proportional to its frequency. Lines joining haplotypes represent one mutation and small lines are missing haplotypes (not sampled or extinct). The shade/s of the circle represents the water color of the sampling locality. "*Ancestral haplotype' denotes the haplotypes considered as ancestral based on statistical parsimony. 


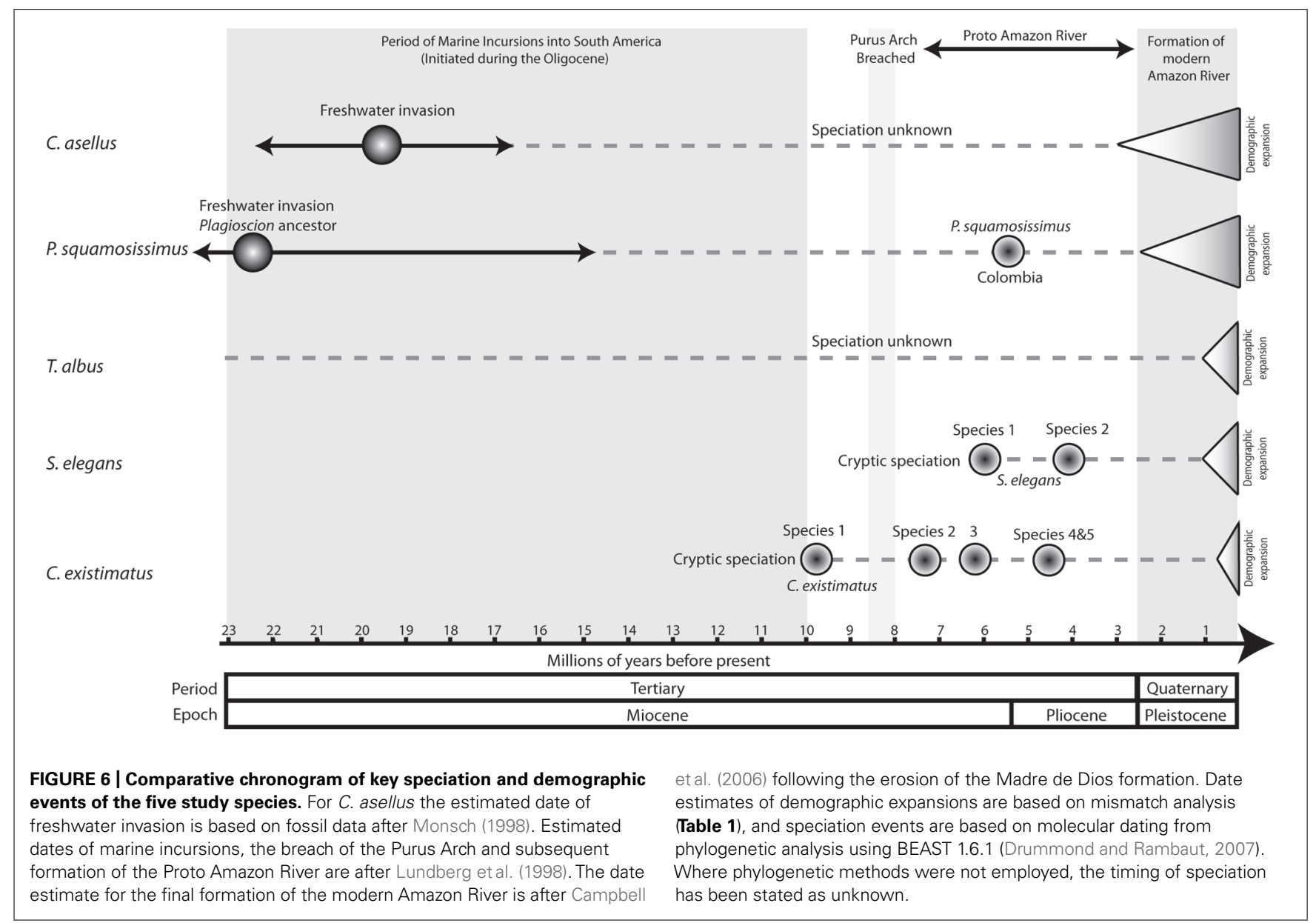

From a population genetic perspective, all species and species complexes showed a predominant barrier to gene flow at the confluence of the Negro and the Amazon Rivers, and/or again at the confluence of the Tapajós and Amazon Rivers (Figures 4 and 5). No significant barrier to gene flow was identified at the confluence of the Madeira and Amazon Rivers in any species. Indeed, based on both mitochondrial and nuclear datasets, population

structure was strongly associated with 'water color' but not with river system. For instance, statistically significant differentiation was consistently found between populations from rivers of different colors, but not between those from rivers of the same color (Tables 2 and 3; Figure 4). For C. existimatus, the large number of inferred cryptic species resulted in insufficient data for intraspecific analysis. However, the C. existimatus cryptic

Table 1 | Historical demographic analyses based on DNA sequences for all species and species complexes.

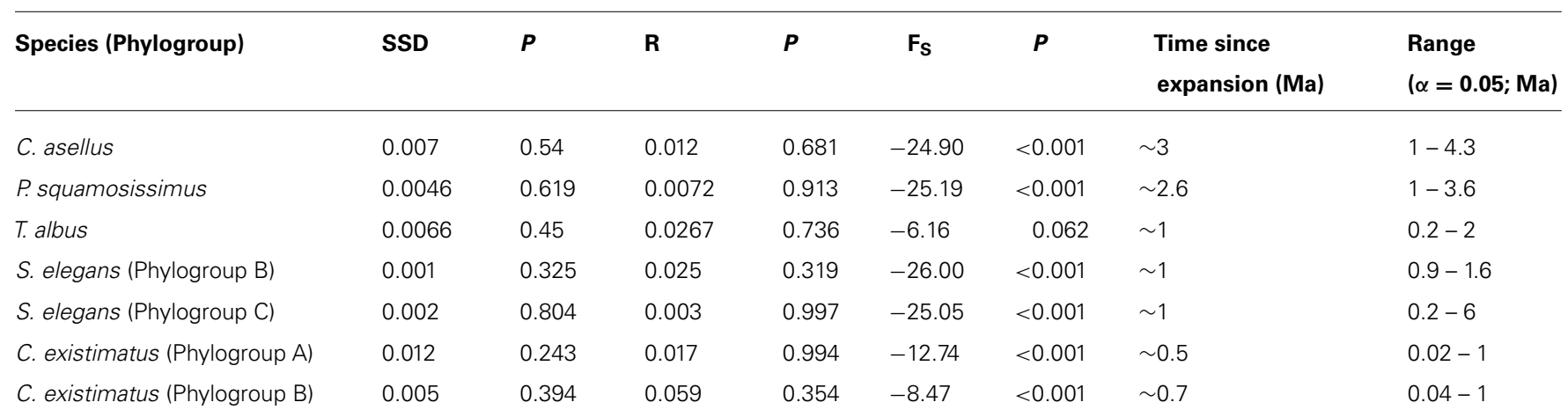

Summaries include the Sum of squared deviations (SSD), Raggedness Index (R), and Fu's test of neutrality (FS). Estimates of time since expansion are shown for analyses exhibiting evidence of demographic expansion. Phylogroups correspond with haplotype networks in Figure 2. 
Table 2 | Analysis of molecular variance (AMOVA) based on mtDNA sequences for three study species.

\begin{tabular}{|c|c|c|c|c|c|c|c|c|}
\hline \multirow[b]{2}{*}{ Species } & \multicolumn{4}{|c|}{ Black vs. white water or white vs. clear water } & \multicolumn{4}{|c|}{ White vs. white water } \\
\hline & Source of Variation & $\%$ Variation & $\mathbf{F I}$ & $P$ & Source of Variation & $\%$ Variation & $\mathbf{F I}$ & $\boldsymbol{P}$ \\
\hline \multirow{2}{*}{ C. asellus } & Between populations & 3.29 & $\Phi_{S C}: 0.0494$ & $0.002^{*}$ & Between populations & 15.36 & $\Phi_{S C}: 0.1514$ & $0.000^{*}$ \\
\hline & Between individuals & 63.21 & $\Phi_{S T}: 0.3679$ & $0.000^{*}$ & Between individuals & 86.09 & $\Phi_{\mathrm{ST}}: 0.1391$ & $0.000^{*}$ \\
\hline & Between populations & 3.72 & $\Phi_{\text {SC }}: 0.050$ & $0.010^{*}$ & Between populations & 6.04 & $\Phi_{\mathrm{SC}}: 0.059$ & $0.012^{*}$ \\
\hline & Between individuals & 71.21 & $\Phi_{\mathrm{ST}}: 0.288$ & $0.000^{*}$ & Between individuals & 96.87 & $\Phi_{\mathrm{ST}}: 0.031$ & $0.015^{*}$ \\
\hline \multirow[t]{3}{*}{ T. albus } & Between water colors & 46.29 & $\Phi_{C T}: 0.463$ & $0.008^{*}$ & Between white water & -27.16 & $\Phi_{\mathrm{CT}}:-0.272$ & 0.665 \\
\hline & Between populations & 13.50 & $\Phi_{\text {SC }}: 0.251$ & $0.000^{*}$ & Between populations & 45.09 & $\Phi_{\mathrm{SC}}: 0.355$ & $0.000 *$ \\
\hline & Between individuals & 40.21 & $\Phi_{\mathrm{ST}}: 0.598$ & $0.000^{*}$ & Between individuals & 82.08 & $\Phi_{\mathrm{ST}}: 0.179$ & $0.000 *$ \\
\hline
\end{tabular}

Comparisons 'between water colors' are based on populations grouped according to river color. Fl stands for Fixation Index, significant results are indicated by*.

Table 3 | Analysis of molecular variance (AMOVA) based on AFLP data for three species and species complex.

\begin{tabular}{|c|c|c|c|c|c|c|c|c|}
\hline Species & Source of Variation & $\%$ Variation & $\mathbf{F I}$ & $P$ & Source of Variation & $\%$ Variation & $\mathbf{F I}$ & $P$ \\
\hline & Between populations & 7.00 & $\Phi_{P R}: 0.067$ & $0.000^{*}$ & Between populations & 8.00 & $\Phi_{\mathrm{PR}}: 0.081$ & $0.000^{*}$ \\
\hline & Between individuals & 91.00 & $\Phi_{\mathrm{PT}}: 0.095$ & $0.000^{*}$ & Between individuals & 92.00 & $\Phi_{\mathrm{PT}}: 0.081$ & $0.000^{*}$ \\
\hline & Between populations & 5 & $\Phi_{P R}: 0.053$ & $0.000^{*}$ & Between populations & 4 & $\Phi_{\mathrm{PR}}: 0.045$ & $0.000^{*}$ \\
\hline & Between individuals & 92 & $\Phi_{\mathrm{PT}}: 0.079$ & $0.000^{*}$ & Between individuals & 94 & $\Phi_{\mathrm{PT}}: 0.058$ & $0.000^{*}$ \\
\hline S. elegans & Between water colors & 6 & $\Phi_{\mathrm{RT}}: 0.060$ & $0.001 *$ & Between white water & 2 & $\Phi_{R T}: 0.017$ & 0.298 \\
\hline \multirow[t]{2}{*}{ (Species 1) } & Between populations & 1 & $\Phi_{P R}: 0.009$ & 0.272 & Between populations & 4 & $\Phi_{\mathrm{PR}}: 0.042$ & 0.174 \\
\hline & Between individuals & 93 & $\Phi_{\mathrm{PT}}: 0.069$ & $0.002^{*}$ & Between individuals & 94 & $\Phi_{\text {Рт }}: 0.058$ & 0.024 \\
\hline
\end{tabular}

Comparisons 'between water colors' are based on populations grouped according to river color. Fl stands for Fixation Index, significant results are indicated by *.

species 'D' endemic to black waters of the Negro River, appeared recently derived and genetically distinct from white water lineages (Figure 5v).

Remarkably, ecologically driven divergence was also depicted in replicate over the riverscape in the two sympatric cryptic species discovered within the electric fish S. elegans. Here, intraspecific divergence within both sp. 1 and sp. 2 is due to a barrier to gene flow between black and white water, whereas no barrier to gene flow was identified between white water rivers (Figure 7; Table 2). These lineages likely exemplify "natural replicates of the ecological speciation in progress" (sensu Rosenblum and Harmon, 2011) and as such should assist with the discovery of general rules about divergent natural selection that may result in ecological speciation (Cooke et al., 2014).

Using outlier loci approaches based on genome scans, divergent selection was quantified between populations of C. asellus, T. albus and S. elegans. Heightened selection was detected at the interface of different water colors in the three species (Table 4), irrespective of river system and tributary arrangement.

\section{SIMULATING ELG ALONG THE AMAZON RIVERSCAPE}

Here we describe an ELG approach that incorporates selection to simulate genetic exchange along the Amazonian riverscape. Although this was used to explore the reasons behind the black water/white water population boundary detected in the electric fish S. elegans (Figure 8; Cooke et al., 2014), such approach can be readily extended to a wide range of studies of ecological speciation.

Simulations were conducted in the individual-based landscape genetics program CDPOP v1.2 (Landguth and Cushman, 2010; Landguth et al., 2012). Individual genetic exchange was simulated for over 100 non-overlapping generations as a function of individual-based movement, mating, dispersal, and 

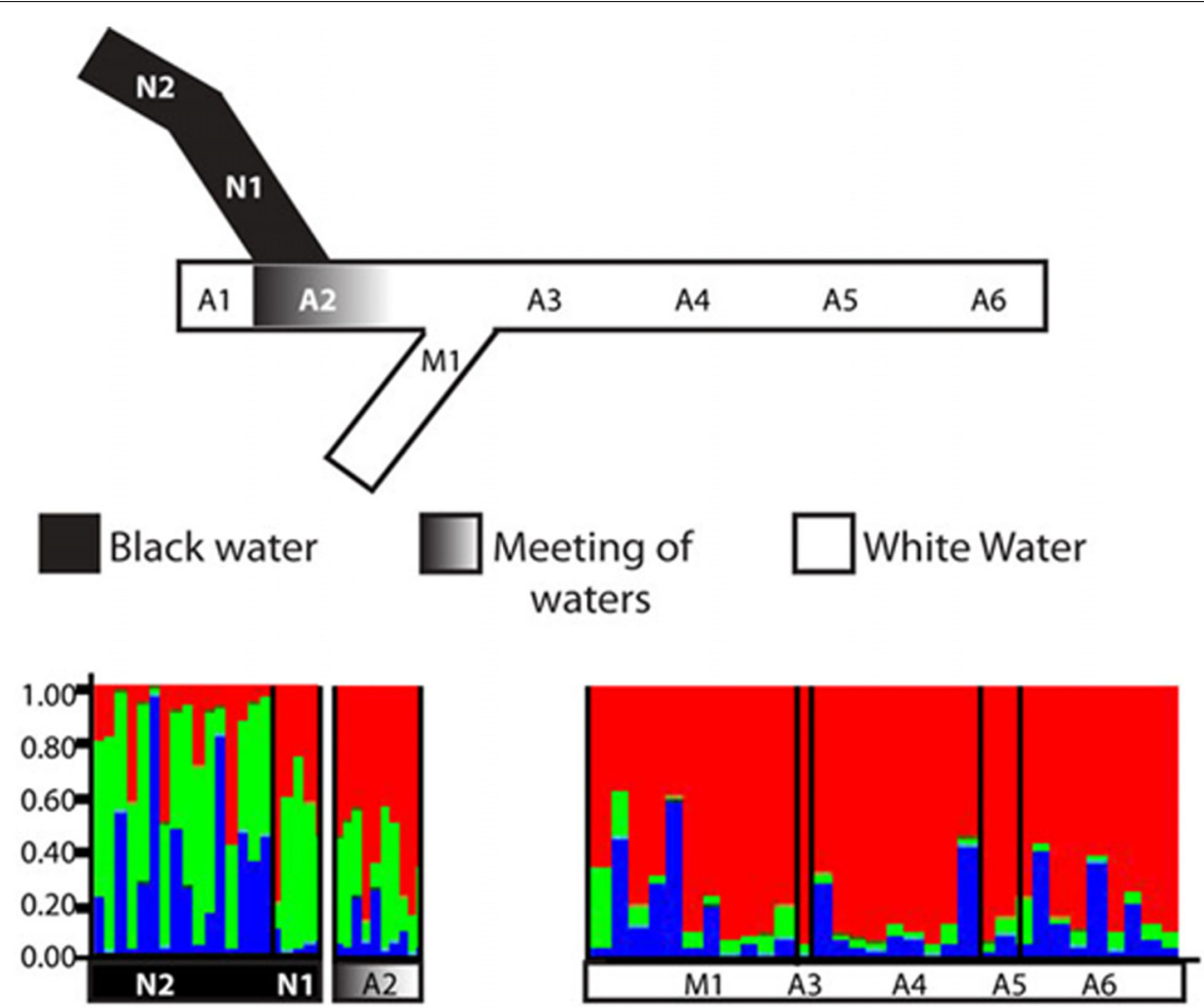

A Species 1
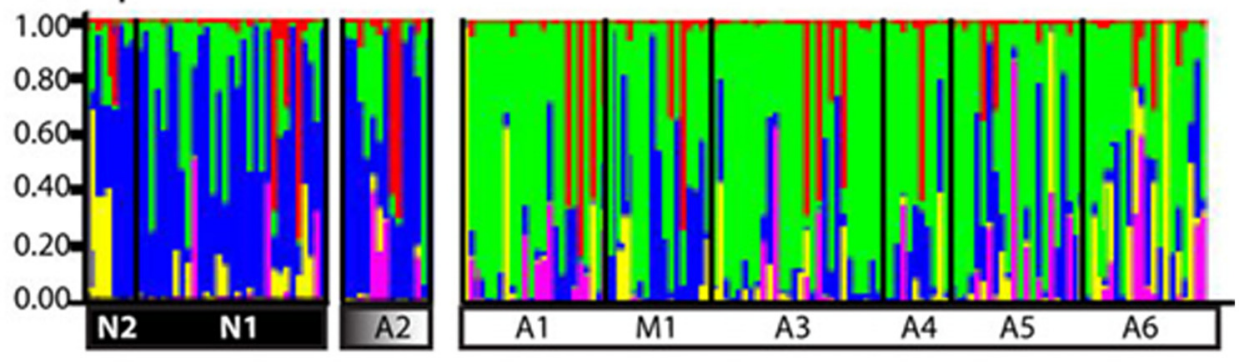

\section{B Species 2}

FIGURE 7 | Replicated ecological divergence in Amazonia due to water color in sympatric cryptic species of the electric fish $S$. elegans. The diagram shows STRUCTURE results for (A) cryptic

species $1(n=62)$ and for (B) cryptic species $2(n=171)$.

Individuals are grouped by sampling location, and each individual is represented by one vertical column. Sample sites and water colors as listed on STRUCTURE graphs correspond to the sampling locations as shown in the simplified map above the graphs. Site abbreviations are: N, Negro River; A, Amazon River, M; Madeira River. Reproduced from Cooke etal. (2014). selection, using 100 individuals spatially located at each of the nine populations in the study system. One locus was set to be under spatial selection and tied to 'water color,' and 19 loci were selectively neutral across a riverine distance surface that controlled for individual movement (mating and dispersal). Following similar studies (e.g., Landguth and Balkenhol, 2012) and expanding to a spatially explicit environmental gradient in a riverscape setting (see Figure 8), selection pressures were altered due to 'water color' between populations by considering three spatially explicit relative fitness surface scenarios. (i) No spatial selection gradient ('uniform'): in this scenario, the three genotypes (AA, Aa, and aa) were being selected against, but uniformly across the 'water color' riverscape scenario, thus having no spatial dependency. (ii) Gentle spatial selection gradient ('gentle'): here, a 'gentle' spatial selection gradient corresponding to the three river color locations and three genotypes was used. (iii) Steep spatial selection gradient ('steep'): for this scenario, stronger spatial selection gradients were assigned to each genotype for black, mixed, and white waters. For further details, see Cooke et al. (2014).

In the $S$. elegans replicated system, population genetic analyses and $F_{\mathrm{ST}}$-based genome scans showed that recent divergence appeared linked to a major hydrochemical gradient within each cryptic species (Tables 3 and 4; Figure 8). Results from ELG simulations further corroborate these findings. These ELG 
Table 4 | The average number of repeat outlier loci for pairwise comparisons between sites for three study species.

\begin{tabular}{llll}
\hline Species & Black vs. White & White vs. White & White vs. Clear \\
\hline $\begin{array}{l}\text { Colomesus } \\
\text { asellus }\end{array}$ & NA & 3.6 & 5.5 \\
$\begin{array}{l}\text { Triportheus albus } \\
\text { Steatogenys }\end{array}$ & 14 & 1.6 & 3 \\
elegans (sp. 2) & & 1.3 & $\mathrm{NA}$ \\
\end{tabular}

Repeat outliers are those detected only in multiple comparisons, which corrects for type I errors. The ALFP data are based on 460 polymorphic loci for $C$. asellus, 360 polymorphic loci for T. albus and 310 polymorphic loci for S. elegans. NA, samples not available.

simulations show that neutral data can give a low population differentiation signal (similar to the empirical neutral data findings based on AFLPs). They also show that selection-driven loci can respond with high population differentiation to the water color ecotone (similar to the empirical outlier loci findings).

The results link selection across an ecological gradient with reproductive isolation and it was speculated that assortative mating based on chemically different water types may be driving the divergence (Cooke etal., 2014). The rationale is that the major differences in $\mathrm{pH}$ and conductivity between waters of the Negro and Amazonas influence the transmission of electric signals used for courtship signaling and for precise synchronization of external fertilization - a hypothesis consistent with the idea that electric discharges in African electric fish are drivers of sympatric speciation (Feulner et al., 2006).

\section{EVOLUTIONARY PROCESSES SHAPPING AMAZONIAN FISH DIVERSITY: GEOMORPHOLOGICAL HISTORY AND DIVERGENT NATURAL SELECTION}

The palaeogeographic and paleoenvironmental changes in South America during the Miocene are known to have profoundly affected the evolution of the Amazonian fish fauna. These changes include the uplift of the Andes and associated neotectonic events,

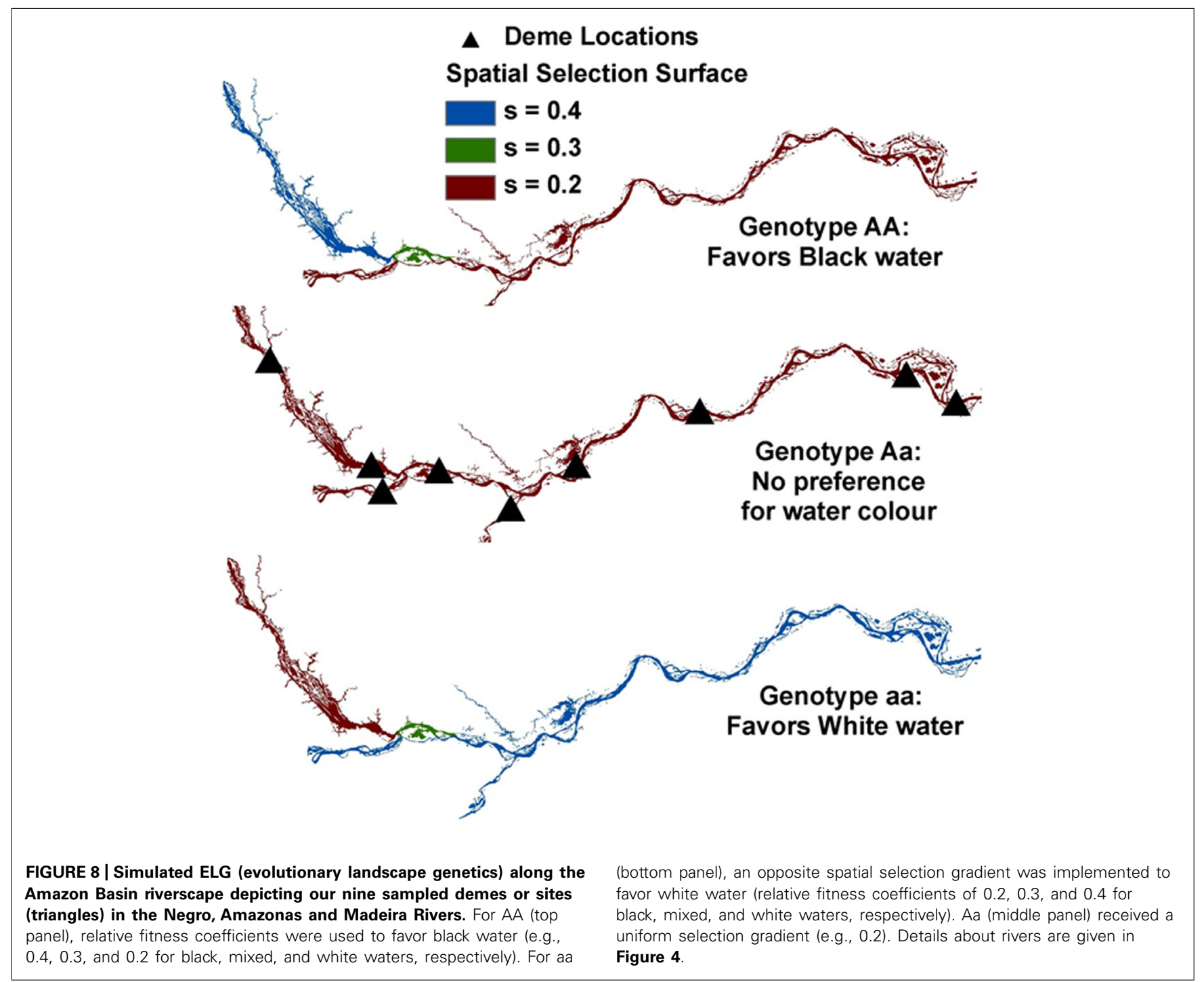


the incursion of marine waters into previously freshwater systems and the dramatic reorientation of major river drainages (e.g., the Amazon River), (Lundberg et al., 1998; Lovejoy and Collette, 2001; Montoya-Burgos, 2003; Hubert and Renno, 2006; Lovejoy et al., 2006; Ruzzante et al., 2006; Hubert et al., 2007; Sistrom et al., 2009; Hoorn et al., 2010a,b; Cooke et al., 2012b,c,d). Indeed, phylogenetic analyses combined with fossil data indicate that the early Miocene marine incursions were likely responsible for the colonization and adaptation to freshwaters of the two marine-derived lineages we studied (Figure 6). Moreover, dating of speciation events within Plagioscion, S. elegans and C. existimatus are consistent with the Miocene diversification of fishes observed in the fossil record, as well as in other molecular studies (Rull, 2008; Sistrom et al., 2009; Piggott et al., 2011). Moving further in time, our analyses detected phylogeographic signals supporting easterly trajectories of colonization down the Amazon River and consistently strong demographic expansions for all species dated for the Quaternary (Figures 5 and 6; Table 1). These studies also suggest that the ancestral ecotype for each species was in Andean-derived white water (Cooke et al., 2012b,c,d, 2014). These events of population history are likely correlated with the final establishment of the modern Amazon River during late Pliocene-early Pleistocene (Rossetti et al., 2005; Campbell et al., 2006). This association was attributed to the availability of novel aquatic habitats along the vast Amazon and its catchment, which enabled range expansions and left concordant records in the population genealogies of codistributed species (Figure 6).

Although palaeogeographic events have clearly contributed to Amazonian fish diversity, the comparative analysis indicates that the force of divergent natural selection, in this case between water colors, deserves equal consideration. One of the primary tenets of ecological speciation theory is that high ecological opportunity, such as the colonization of new environments in the absence of predation and/or competition, will promote rapid population divergence resulting in speciation (Mayr, 1963; Schluter, 2000). Indeed, adaptive radiations following the colonization of new habitats are well documented in fish (Bernatchez and Wilson, 1998; Beheregaray et al., 2002). The simultaneous Quaternary expansion events of the five species into the Amazon River system may have presented the high ecological opportunity necessary for divergent natural selection and adaptation between Andean (white) and Craton-derived (black and clear) waters.

Classic signatures of vicariant biogeographic history such as genetic drift, inbreeding and migration have genome wide effects, while selection usually leaves signatures only at those loci that are adaptive or tightly linked to adaptive loci via hitchhiking (Luikart et al., 2003; Jensen et al., 2007). For this reason, $F_{\text {ST }}$-based genome scans were employed to assess the role of selection in the origin and maintenance of population divergence between water colors. However, key to ecologically based divergent natural selection is that the process should be greater between selective environments than within (Schluter and Conte, 2009). Indeed, in each species, more outlier loci on average were found in pairwise comparisons between different water colors than in comparisons between the same colors (Table 4).

For C. asellus, divergent selection detected between the Tapajós and Amazon Rivers was a powerful yet recent phenomenon, such that genetic drift had not yet accumulated in selectively neutral genomic regions (Cooke et al., 2012b). In contrast, the effects of isolation by environment was suggested for T. albus between black, white and clear waters (Cooke et al., 2012a). For that species, a population boundary between water colors has also arisen within the selectively neutral AFLP loci and is particularly marked in the mitochondrial data (Figure 5iii). For S. elegans, both the empirical landscape genetics and simulated ELG explicitly linked selectiondriven population genetic structure to the water color ecotone, validating results of $F_{\mathrm{ST}}$-based genome scans. By incorporating information about population history and by independently validating outlier results with simulations, we improved our ability to exclude type 1 errors normally associated with genome scans of selection (see Cooke et al., 2014 for details).

In the context of comparative biology, the use of genome scans revealed variable, yet valuable perspectives on the process of adaptive divergence across water colors, both within and between species. Although there is no certainty that ecologically diverged lineages will eventuate as reproductively isolated species (Futuyma, 1987; Via, 2009), the observation of isolation by environment within T. albus and speciation in the S. elegans complex across the same environmental gradient added credence to the assertion that water color is a general force shaping Amazonian freshwater biodiversity. Considering this, it may also be likely that divergent natural selection is the mechanism maintaining population boundaries observed between water colors for P. squamosissimus and C. existimatus (Figures 5ii, v).

The evidence for the role of divergent natural selection in these studies occupies a relatively recent time frame and appears associated with the formation of the modern Amazon River and its aquatic ecotones. Considering that time erases the signature of divergent selection within the genome, resulting in a more diffuse pattern of genetic divergence (Via, 2009), ecological speciation may not be just a recent phenomenon within the Amazon Basin. Here, a broad taxonomic range of species with different life histories were sampled and in every case there was evidence that water color influenced population divergence. Thus, the process of divergent natural selection is also likely to be widespread in the accumulation of contemporary diversity, which may shift the paradigm for future evolutionary research in Amazonia.

\section{FUTURE DIRECTIONS}

Clarifying the role of ecology on population adaptation and divergence is crucial for understanding the origin of species and the evolutionary potential of biodiversity to respond to ongoing global change (Hoffmann and Sgro, 2011; Seehausen et al., 2014). Although the theory of adaptation is well developed, measuring the strength and characteristics of selection in nature remains a daunting task (Endler, 1986; Schluter, 1988; Jones et al., 2012). We generally lack knowledge about the genomic basis of population adaptation and divergence, especially for tropical organisms. Despite these gaps in knowledge, recent years have seen exciting developments due to the explosion of information for non-model organisms created by NGS technologies. While modest genetic datasets can certainly inform on ecological divergence that may result in ecological speciation (e.g., Cooke et al., 2012a,b, 2014), it is now feasible to 'genomicize' ecologically and 
evolutionarily important species at relatively low costs (Travers et al., 2007; Ellegren, 2008; Bernatchez et al., 2010; Seehausen et al., 2014). NGS resources relevant for ecological speciation research include genome-wide marker panels for population genomics, whole genome sequences and transcriptomes. These can be used to identify gene regions and traits involved in adaptation, to understand selective factors influencing adaptive variation and to assess evolutionary resilience.

As illustrated in this review, studies of ecological speciation in the tropics should merge analyses of genealogical history and gene flow with recent developments in spatial modeling and ELG simulations. This integration provides valuable biogeographic and environmental contexts to disclose associations between landscape features and evolutionary processes, including divergent natural selection. Such approaches, when combined with NGS datasets and with information about divergent phenotypes can be used to identify adaptive loci across the landscape (Lowry, 2010; Schoville et al., 2012), and to better assess the relative sensitivity of adaptive and neutral loci across environmental barriers and under a range of gene flow (Balkenhol and Landguth, 2011). However, researchers have to unambiguously determine whether markers are under selection and undoubtedly, this multigenic process encompasses additive, epistatic interaction, and pleiotropic effects. While several analytical challenges remain, ELG simulations in combination with powerful genomic datasets can provide a snapshot of the potential of evolutionary processes. Future research should address how landscape heterogeneity affects the generation of cluster of reproductively isolated genotypes through landscape restricted migration. Furthermore, how do spatial selection gradients influence the emergence of reproductively isolating clusters? These questions have direct relevance for mosaic hybrid zones (e.g., Ross and Harrison, 2002) and how they are shaped by individualbased movement strategies, heterogeneous landscapes, spatial selection gradients, and their interactions. Forthcoming ELG simulations should combine a range of landscape complexities (affecting dispersal) with spatial selection gradients and complex endogenous selection (i.e., multi-loci interactions, recombination, and mutational models) within the framework outlined here to understand processes controlling the emergence of reproductive isolation.

Ecological adaptation and divergence in the face of homogenizing gene flow is still a controversial topic. Many studies of ecological speciation in nature appear as correlative, are based on results from lab experiments (Nosil, 2012), and showed only weak associations between divergent selection and levels of reproductive isolation (Hendry, 2009). The latter is not unexpected because divergent selection acts on adaptive traits responsible for post- and prezygotic reproductive isolation along an evolutionary continuum that ranges from adaptive variation within panmictic populations to complete reproductive isolation between species (Schluter, 2001; Hendry, 2009). In fact, a recent meta-analysis suggests that genetic divergence induced by ecologically based divergent selection is pervasive across time-scales and taxa (Shafer and Wolf, 2013). Marine ecosystems are no exception, with two decades of phylogeographic research indicating that the combination of ecological divergence and partial isolation (parapatry) probably offers the richest opportunities for diversification in the sea (Bowen et al., 2013).

The time is right for implementing studies that synergistically generate and explore information from adaptive phenotypes, phylogeography, population genomics and simulations in ELG to understand ecological divergence and speciation in the tropics. Such endeavors are expected to challenge results from current surveys that assess tropical diversity based on sparse population sampling and on geographic models that do not incorporate selection. In doing so, they will complement historical biogeographic and evolutionary studies of diversification of tropical biotas. Integrative frameworks such as the one illustrated here have considerable potential to enhance conservation management in biodiversity rich ecosystems and to contribute toward a better understanding of how ecology, space and time interact with the genome.

\section{ACKNOWLEDGMENTS}

We thank Peter Teske and two reviewers for comments on the manuscript and Minami Sasaki and Luisa Beheregaray for assistance with the references and data entry, respectively. The Amazonian research outlined here was funded by the Discovery Program of the Australian Research Council (ARC DP0556496 to LBB) and by Macquarie University through postgraduate travel and student grants to GMC. Local arrangements were supported in part by the Brazilian Council of Research and Technology (CNPqSEAP No. 408782/2006-4 to NLC). Collection permit is under IBAMA\#1920550, and ethical approval under Macquarie University \#2007/033. LBB also acknowledges support from the ARC Future Fellowship program (FT130101068).

\section{REFERENCES}

Antonelli, A., and Sanmartín, I. (2011). Why are there so many plant species in the Neotropics? Taxon 60, 403-414.

Avise, J. C. (1992). Molecular population-structure and the biogeographic history of a regional fauna - a case history with lessons for conservation biology. Oikos 63, 62-76. doi: $10.2307 / 3545516$

Avise, J. C. (2000). Phylogeography: The History and Formation of Species. Cambridge, MA: Harvard University Press.

Avise, J. C., Walker, D., and Johns, G. C. (1998). Speciation durations and Pleistocene effects on vertebrate phylogeography. Proc. Biol. Sci. 265, 1707-1712. doi: 10.1098/rspb.1998.0492

Balkenhol, N., and Fortin, M.-J. (2014). "Chapter 4: Sampling," in Landscape Genetics, eds N. Balkenhol, L. Waits, and S. Cushman (London: Wiley). in press.

Balkenhol, N., and Landguth, E. L. (2011). Simulation modeling in landscape genetics: on the need to go further. Mol. Ecol. 20, 667-670. doi: 10.1111/j.1365-294X.2010.04967.x

Balloux, F. (2001). EASYPOP (version 1.7): a computer program for population genetic simulations. J. Hered. 92, 301-302. doi: 10.1093/jhered/92.3.301

Beaumont, M. A. (2005). Adaptation and speciation: what can F-st tell us? Trends Ecol. Evol. 20, 435-440. doi: 10.1016/j.tree.2005.05.017

Beheregaray, L. B. (2008). Twenty years of phylogeography: the state of the field and the challenges for the Southern Hemisphere. Mol. Ecol. 17, 3754-3774. doi: 10.1111/j.1365-294X.2008.03857.x

Beheregaray, L. B., and Caccone, A. (2007). Cryptic biodiversity in a changing world. J. Biol. 6:9. doi: 10.1186/jbiol60

Beheregaray, L. B., Havill, N., Gibbs, J., Fritts, T., Powell, J. R., and Caccone, G. (2004). Giant tortoises are not so slow: rapid diversification and biogeographic consensus in the Galápagos. Proc. Natl. Acad. Sci. U.S.A. 101, 6514-6519. doi: 10.1073/pnas.0400393101

Beheregaray, L. B., and Sunnucks, P. (2001). Fine-scale genetic structure, estuarine colonization and incipient speciation in the marine silverside fish Odontesthes 
argentinensis. Mol. Ecol. 10, 2849-2866. doi: 10.1046/j.1365-294X.2001.t01-101406.x

Beheregaray, L. B., Sunnucks, P., and Briscoe, D. A. (2002). A rapid fish radiation associated with the last sea level changes in southern Brazil: the silverside Odontesthes perugiae complex. Proc. Biol. Sci. 269, 65-73. doi: 10.1098/rspb.2001.1838

Bernatchez, L., Renaut, S., Whiteley, A. R., Derome, N., Jeukens, J., Landry, L., et al. (2010). On the origin of species: insights from the ecological genomics of lake whitefish. Philos. Trans. R. Soc. B Biol. Sci. 365, 1783-1800. doi: 10.1098/rstb.2009.0274

Bernatchez, L., and Wilson, C. C. (1998). Comparative phylogeography of nearctic and palearctic fishes. Mol. Ecol. 7, 431-452. doi: 10.1046/j.1365294x.1998.00319.x

Bowen, B. W., Rocha, L. A., Toonen, R. J., Karl, S. A., Craig, M. T., DiBattista, J. D., et al. (2013). The origins of tropical marine biodiversity. Trends Ecol. Evol. 28, 359-366. doi: 10.1016/j.tree.2013.01.018

Campbell, K. E., Frailey, C. D., and Romero-Pittman, L. (2006). The Pan-Amazonian Ucayali Peneplain, late Neogene sedimentation in Amazonia, and the birth of the modern Amazon River system. Palaeogeogr. Palaeoclimatol. Palaeoecol. 239, 166-219. doi: 10.1016/j.palaeo.2006.01.020

Carnaval, A. C., Moritz, C., Hickerson, M., Haddad, C., and Rodrigues, M. (2009). Stability predicts diversity in the Brazilian Atlantic Forest hotspot. Science 323, 785-789. doi: 10.1126/science.1166955

Carstens, B. C., and Knowles, L. L. (2006). Shifting distributions and speciation: genomic resolution of species divergence during rapid climate change. Mol. Ecol. 16, 6619-6627. doi: 10.1111/j.1365-294X.2006.03167.x

Cooke, G. M., Chao, N. L., and Beheregaray, L. B. (2009). Phylogeography of a flooded forest specialist fish from central Amazonia based on intron DNA the cardinal tetra paracheirodon axelrodi. Freshw. Biol. 54, 1216-1232. doi: 10.1111/j.1365-2427.2009.02172.x

Cooke, G. M., Chao, N. L., and Beheregaray, L. B. (2012a). Divergent natural selection with gene flow along major environmental gradients in Amazonia: insights from genome scans, population genetics and phylogeography of the characin fish Triportheus albus. Mol. Ecol. 21, 2410-2427. doi: 10.1111/j.1365294X.2012.05540.x

Cooke, G. M., Chao, N. L., and Beheregaray, L. B. (2012b). Natural selection in the water: freshwater invasion and isolation by adaptation to water colour in the Amazonian pufferfish. J. Evol. Biol. 25, 1305-1320. doi: 10.1111/j.14209101.2012.02514.x

Cooke, G. M., Chao, N. L., and Beheregaray, L. B. (2012c). Marine incursions, cryptic species and ecological diversification in Amazonia: the biogeographic history of the croaker genus Plagioscion (Sciaenidae). J. Biogeogr. 39, 724-738. doi: 10.1111/j.1365-2699.2011.02635.x

Cooke, G. M., Chao, N. L., and Beheregaray, L. B. (2012d). Five cryptic species in the Amazonian catfish Centromochlus existimatus identified based on biogeographic predictions and genetic data. PLoS ONE 7:e48800. doi: 10.1371/journal.pone.0048800

Cooke, G. M., Landguth, E. L., and Beheregaray, L. B. (2014). Riverscape genetics identifies replicated ecological divergence across an Amazonian ecotone. Evolution 68, 1947-1960. doi: 10.1111/evo.12410

Corlett, R., and Primack R. B. (2010). Tropical Rainforests: An Ecological and Biogeographical Comparison. Malden, MA: Wiley-Blackwell.

Coyne, J. A. (2007). Sympatric speciation. Curr. Biol. 17, R787-R788. doi: 10.1016/j.cub.2007.06.056

Coyne, J. A., and Orr, H. A. (2004). Speciation. Sunderland, MA: Sinauer Associates

Darwin, C. (1859). On the Origin of Species, 6th Edn. London: Murray.

Davis, E. B., Koo, M. S., Conroy, C., Patton, J. L., and Moritz, C. (2008). The California hotspots project: identifying regions of rapid diversification of mammals. Mol. Ecol. 17, 120-138. doi: 10.1111/j.1365-294X.2007.03469.x

Dawson, M. N., Algar, A. C., Antonelli, A., Davalos, L. M., Davis, E., Early, R., etal. (2013). An horizon scan of biogeography. Front. Biogeogr. 5: 130-157.

Dobzhansky, T. (1937). Genetics and the Origin of Species. New York, NY: Columbia University Press.

Dobzhansky, T. (1970). Genetics of the Evolutionary Process. New York, NY: Columbia University Press.

Drummond, A., and Rambaut, A. (2007). BEAST: Bayesian evolutionary analysis by sampling trees. BMC Evol. Biol. 7:214-221. doi: 10.1186/1471-2148-7-214
Ellegren, H. (2008). Comparative genomics and the study of evolution by natural selection. Mol. Ecol. 17, 4586-4459. doi: 10.1111/j.1365-294X.2008.03954.x

Endler, J. A. (1973). Gene flow and population differentiation. Science 179, 243-250. doi: 10.1126/science.179.4070.243

Endler, J. A. (1977). Geographic Variation, Speciation, and Clines. Princeton: Princeton University Press.

Endler, J. A. (1982). Problems in distinguishing historical from ecological factors in biogeography. Am. Zool. 22, 441-452.

Endler, J. A. (1986). Natural Selection in the Wild. Princeton: Princeton University Press.

Eppstein, M. J., Payne, J. L., and Goodnight, C. J. (2009). Underdominance, multiscale interactions, and self-organizing barriers to gene flow. J. Artif. Evol. Appl. 2009:725049. doi: 10.1155/2009/725049

Epstein, J. M. (2007). "Remarks on the role of modeling in infectious disease mitigation and containment," in Ethical and Legal Considerations in Mitigating Pandemic Disease: Workshop Summary. Forum on Microbial Threats, eds S. M. Lemon, M. A. Hamberg, F. Sparling, E. R. Choffnes, and A. Mack (Washington: National Academies Press).

Excoffier, L., Smouse, P. E., and Quattro, J. M. (1992). Analysis of molecular variance inferred from metric distances among DNA haplotypes: application to human mitochondrial DNA restriction data. Genetics 131, 479-491.

Falush, D., Stephens, M., and Pritchard, J. K. (2003). Inference of population structure: extensions to linked loci and correlated allele frequencies. Genetics 164, 1567-1587.

Feulner, P. G., Kirschbaum, F., Schugardt, C., Ketmaier, V., and Tiedemann, R. (2006). Electrophysiological, and molecular genetic evidence for sympatrically occuring cryptic species in African weakly electric fishes (Teleostei: Mormyridae: Campylomormyrus). Mol. Phylogenet. Evol. 39, 198-208. doi: 10.1016/j.ympev.2005.09.008

Funk, D. J. (1998). Isolating a role for selection in speciation: host adaptation and sexual isolation in Neochlamisus behbianae leaf beetles. Evolution 52, 1744-1759. doi: $10.2307 / 2411347$

Funk, W. C., Caminer, M., and Ron, S. R. (2012). High levels of cryptic species diversity uncovered in Amazonian frogs. Proc. R. Soc. B Biol. Sci. 279, 1806-1814. doi: $10.1098 / \mathrm{rspb} .2011 .1653$

Futuyma, D. J. (1987). On the role of species in Anagenesis. Am. Nat. 130, 465-473. doi: $10.1086 / 284724$

Galarza, J. A., Carreras-Carbonell, J., Macpherson, E., Pascual, M., Roques, S., Turner, G. F., et al. (2009). The influence of oceanographic fronts and early-lifehistory traits on connectivity among littoral fish species. Proc. Natl. Acad. Sci. U.S.A. 106, 1473-1478. doi: 10.1073/pnas.0806804106

Garcia-Paris, M., Good, D. A., Parra-Olea, G., and Wake, D. B. (2000). Biodiversity of Costa Rican salamanders: implications of high levels of genetic differentiation and phylogeographic structure for species formation. Proc. Natl. Acad. Sci. U.S.A. 97, 1640-1647. doi: 10.1073/pnas.97.4.1640

Gavrilets, S. (2004). Fitness Landscapes and the Origin of Species. Princeton, NJ: Princeton University Press.

Grimm, V., and Railsback, S. F. (2005). Individual-based modeling in ecology. Oxford: Princeton University Press.

Haffer, J. (1997). Alternative models of vertebrate speciation in Amazonia: an overview. Biodivers. Conserv. 6, 451-477. doi: 10.1023/A:1018320925954

Harrison, R. G. (2012). The language of speciation. Evolution 66, 3643-3657. doi: 10.1111/j.1558-5646.2012.01785.x

Henderson, P. A., and Crampton, W. G. R. (1997). A comparison of fish diversity and abundance between nutrient-rich and nutrient-poor lakes in the Upper Amazon. J. Trop. Ecol. 13, 175-198. doi: 10.1017/S0266467400010403

Hendry, A. P. (2009). Ecological speciation! Or the lack thereof? Can. J. Fish. Aquat. Sci. 66, 1383-1398. doi: 10.1139/F09-074

Hewitt, G. M. (2001). Speciation, hybrid zones and phylogeography — or seeing genes in space and time. Mol. Ecol. 10, 537-549. doi: 10.1046/j.1365294x.2001.01202.x

Hoban, S. (2014). An overview of the utility of population simulation software in molecular ecology. Mol. Ecol. 23, 2383-2401. doi: 10.1111/mec.12741

Hoban, S., Bertorelle, G., and Gattiotti, O. E. (2012). Computer simulations: tools for population and evolutionary genetics. Nat. Rev. Genet. 13, 110-122. doi: $10.1038 / \operatorname{nrg} 3130$

Hoffmann, A. A., and Sgro, C. M. (2011). Climate change and evolutionary adaptation. Nature 470, 479-485. doi: 10.1038/nature09670 
Hoorn, C., Roddaz, M., Dino, R., Soares, E., Uba, C., Ochoa-Lozano, D., et al. (2010a). "The Amazonian Craton and its influence on the past fluvial systems (Mesozoic-Cenozoic, Amazonia)," in: Amazonia: Landscape and Species Evolution, a Look into the Past, eds C. Hoorn and F. Wesselingh (West Sussex: Wiley Blackwell).

Hoorn, C., Wesselingh, F. P., Ter Steege, H., Bermudez, M. A., Mora, A., Sevink, J., et al. (2010b). Amazonia through time: Andean uplift, climate change, landscape evolution, and biodiversity. Science 330, 927-931. doi: 10.1126/science.1194585

Hoorn, C., Wesselingh, F. P., Ter Steege, H., Bermudez, M. A., Mora, A., Sevink, J., et al. (2011). Origins of biodiversity-response. Science 331, 399-400. doi: 10.1126/science.331.6016.399

Hubert, N., Duponchelle, F., Nunez, J., Garcia-Davila, C., Paugy, D., and Renno, J. F. (2007). Phylogeography of the piranha genera Serrasalmus and Pygocentrus: implications for the diversification of the Neotropical ichthyofauna. Mol. Ecol. 16, 2115-2136. doi: 10.1111/j.1365-294X.2007.03267.x

Hubert, N., and Renno, J.-F. (2006). Historical biogeography of South American freshwater fishes. J. Biogeogr. 33, 1414-1436. doi: 10.1111/j.13652699.2006.01518.x

Hughes, C., Pennington, R. T., and Antonelli, A. (2013). Neotropical plant evolution assembling the big picture. Bot. J. Linn. Soc. 171, 1-18. doi: 10.1111/boj.12006

Janzen, D. H., Hallwachs, W., Blandin, P., Burns, J. M., Cadiou, J. M., Chacon, I., etal. (2009). Integration of DNA barcoding into an ongoing inventory of complex tropical biodiversity. Mol. Ecol. Resour. 9, 1-26. doi: 10.1111/j.17550998.2009.02628.x

Jeltsch, F., Bonte, D., Pe'er, G., Reineking, B., Leimgruber, P., Balkenhol, N., et al. (2013). Integrating movement ecology with biodiversity research - exploring new avenues to address spatiotemporal biodiversity dynamics. Mov. Ecol. 1:6 doi: 10.1186/2051-3933-1-6

Jensen, J. D., Wong, A., and Aquadro, C. F. (2007). Approaches for identifying targets of positive selection. Trends Genet. 23, 568-577. doi: 10.1016/j.tig.2007.08.009

Jones, F. C., Grabherr, M. G., Chan, Y. F., Russell, P., Mauceli, E., Johnson, J., et al. (2012). The genomic basis of adaptive evolution in threespine sticklebacks. Nature 484, 55-61. doi: 10.1038/nature10944

Junk, W. J., Soares, M. G., and Carvalho, F. M. (1983). Distribution of fish species in a lake of the Amazon River floodplain near Manaus (Lago Camaleao), with special reference to extreme oxygen conditions. Amazoniana 7, 397-431.

Kearney, M. R., Isaac, A. P., and Porter, W. P. (2014). microclim: Global estimates of hourly microclimate based on long-term monthly climate averages. Sci. Data 1:140006. doi: 10.1038/sdata.2014.6

Kearney, M., and Porter, W. (2009). Mechanistic niche modelling: combining physiological and spatial data to predict species' ranges. Ecol. Lett. 12, 334-350. doi 10.1111/j.1461-0248.2008.01277.x

Landguth, E. L., and Balkenhol, N. (2012). Relative sensitivity of neutral versus adaptive genetic data for assessing population differentiation. Conserv. Genet. 13 , 1421-1426. doi: 10.1007/s10592-012-0354-x

Landguth, E. L., and Cushman, S. A. (2010). CDPOP: a spatially explicit cost distance population genetics program. Mol. Ecol. Resour. 10, 156-161. doi: 10.1111/j.17550998.2009.02719.x

Landguth, E. L., Cushman, S. A., and Balkenhol, N. (2014). "Simulation modeling in landscape genetics," in Landscape Genetics, Chap. 6, eds N. Balkenhol, L. Waits, and S. Cushman (London: Wiley), in press.

Landguth, E. L., Cushman, S. A., and Johnson, N. A. (2012). Simulating natural selection in landscape genetics. Mol. Ecol. Resour. 12, 363-368. doi: 10.1111/j.1755-0998.2011.03075.x

Lopez-Fernandez, H., Winemiller, K. O., and Honeycutt, R. L. (2010). Multilocus phylogeny and rapid radiations in Neotropical cichlid fishes (Perciformes: Cichlidae: Cichlinae). Mol. Phylogenet. Evol. 55, 1070-1086. doi: 10.1016/j.ympev.2010.02.020

Losos, J. B., Arnold, S. J., Bejerano, G., Brodie, E. D. III., Hibbett, D., Hoekstra, H. E., et al. (2013). Evolutionary biology for the 21st century. PLoS Biol. 11:e1001466. doi: 10.1371/journal.pbio.1001466

Lovejoy, N. R., Albert, J. S., and Crampton, W. G. R. (2006). Miocene marine incursions and marine/freshwater transitions: evidence from Neotropical fishes. J. South Am. Earth Sci. 21, 5-13. doi: 10.1016/j.jsames.2005. 07.009

Lovejoy, N. R., and Collette, B. B. (2001). Phylogenetic relationships of new world needlefishes (Teleostei: Belonidae) and the biogeography of transitions between marine and freshwater habitats. Copeia 2, 324-338. doi: 10.1643/00458511(2001)001[0324:PRONWN]2.0.CO;2
Lowry, D. B. (2010). Landscape evolutionary genomics. Biol. Lett. 6, 502-504. doi: 10.1098/rsbl.2009.0969

Luikart, G., England, P. R., Tallmon, D., Jordan, S., and Taberlet, P. (2003). The power and promise of population genomics: from genotyping to genome typing. Nat. Rev. Genet. 4, 981-994. doi: 10.1038/nrg1226

Lundberg, J. C., Marshall, L. G., Guerrero, J., Horton, B., Claudia, M., Malabarba, L. R., et al. (1998). "The stage for Neotropical fish diversification: a history of tropical South American rivers," in Phylogeny and Classification of Neotropical Fishes, eds L. R. Malabarba, R. E. Reis, R. P. Vari, Z. M. S. Lucene, and C. A. S. Lucena (Porto Alegre: Edipucrs), 13-48.

Lynch, M., and Milligan, B. G. (1994). Analysis of population genetic structure with rapid markers. Mol. Ecol. 3, 91-99. doi: 10.1111/j.1365-294X.1994.tb00109.x

Manel, S., Joost, S., Epperson, B., Storfer, A., Holderegger, R., Rosenberg, M. S., et al. (2010). Perspectives on the use of landscape genetics to detect genetic adaptive variation in the field. Mol. Ecol. 19, 3760-3772 doi: 10.1111/j.1365294X.2010.04717.x

Mayr, E. (1942). Systematics and the Origin of Species. New York: Columbia University Press.

Mayr, E. (1963). Animal Species and Evolution. Cambridge: Harvard University Press. doi: 10.4159/harvard.9780674865327

Monsch, K. A. (1998). Miocene fish faunas from the northwestern Amazon basin (Colombia, Peru, Brazil) with evidence of marine incursions. Palaeogeogr. Palaeoclimatol. Palaeoecol. 143, 31-50. doi: 10.1016/S0031-0182(98)00064-9

Montoya-Burgos, J. I. (2003). Historical biogeography of the catfish genus Hypostomus (Siluriformes: Loricariidae), with implications on the diversification of Neotropical ichthyofauna. Mol. Ecol. 12, 1855-1867. doi: 10.1046/j.1365294X.2003.01857.x

Moritz, C., Patton, J. L., Schneider, C. J., and Smith, T. B. (2000). Diversification of rainforest faunas: an integrated molecular approach. Annu. Rev. Ecol. Syst. 31, 533-563. doi: 10.1146/annurev.ecolsys.31.1.533

Muller, H. J. (1942). Isolating mechanisms, evolution, and temperature. Biol. Symp. $6,71-125$.

Narum, S., Buerkle, C. A., Davey, J., Miller, M. R., and Hohenlohe, P. A. (2013). Genotyping-by-sequencing in ecological and conservation genomics. Mol. Ecol. 22, 2841-2847. doi: 10.1111/mec. 12350

Nosil, P. (2008). Ernst Mayr and the integration of geographic and ecological factors in speciation. Biol. J. Linn. Soc. 95, 26-26. doi: 10.1111/j.1095-8312.2008.01091.x Nosil, P. (2012). Ecological Speciation. Oxford: Oxford University Press.

Nosil, P., Funk, D. J., and Ortiz-Barrientos, D. (2009). Divergent selection and heterogeneous genomic divergence. Mol. Ecol. 18, 375-402. doi: 10.1111/j.1365294X.2008.03946.x

Ogden, R., and Thorpe, R. S. (2002). Molecular evidence for ecological speciation in tropical habitats. Proc. Natl. Acad. Sci. U.S.A. 99, 13612-13615. doi: 10.1073/pnas.212248499

Orr, M. R., and Smith, T. B. (1998). Ecology and speciation. Trends Ecol. Evol. 13, 502-506. doi: 10.1016/S0169-5347(98)01511-0

Parra-Olea, G., and Wake, D. B. (2001). Extreme morphological and ecological homoplasy in tropical salamanders. Proc. Natl. Acad. Sci. U.S.A. 98, 7888-7891. doi: $10.1073 /$ pnas. 131203598

Pennington, R. T., Lavin, M., Prado, D. E., Pendry, C. A., Pell, S. K., and Butterworth, C. H. (2004). Historical climate change and speciation: Neotropical seasonally dry forest plants show patterns of both Tertiary and Quaternary diversification. Philos. Trans. R. Soc. Lon. B Biol. Sci. 359, 315-338.

Petry, P., Bayley, P. B., and Markle, D. F. (2003). Relationships between fish assemblages, macrophytes and environmental gradients in the Amazon River floodplain. J. Fish Biol. 63, 547-579. doi: 10.1046/j.1095-8649.2003.00169.x

Piggott, M. P., Chao, N. L., and Beheregaray, L. B. (2011). Three fishes in one: cryptic species in an Amazonian floodplain forest specialist. Biol. J. Linn. Soc. 102, 391-403. doi: 10.1111/j.1095-8312.2010.01571.x

Primack, R. B. (2014). Essentials of Conservation Biology. Boston, MA: Sinauer.

Räsänen, K., and Hendry, A. P. (2008). Disentangling interactions between adaptive divergence and gene flow when ecology drives diversification. Ecol. Lett. 11, 624636. doi: 10.1111/j.1461-0248.2008.01176.x

Renaut, S., Grassa, C. J., Yeaman, S., Moyers, B. T., Lai, Z., Kane, N. C., et al. (2013). Genomic islands of divergence are not affected by geography of speciation in sunflowers. Nat. Commun. 4:1827. doi: 10.1038/ncomms2833

Richardson, J. E., Pennington, R. T., Pennington, T. D., and Hollingsworth, P. M. (2001). Rapid diversification of a species-rich genus of neotropical rain forest trees. Science 293, 2242-2245. doi: 10.1126/science.1061421 
Rocha, L. A., Aleixo, A., Allen, G., Almeda, F., Baldwin, C. C., Barclay, M. V., et al. (2014). Specimen collection: an essential tool. Science 344, 814-815. doi: 10.1126/science.344.6186.814

Rodriguez, M. A., and Lewis, W. M. (1997). Structure of fish assemblages along environmental gradients in floodplain lakes of the Orinoco River. Ecol. Monogr 67, 109-128. doi: 10.1890/0012-9615(1997)067[0109:SOFAAE]2.0.CO;2

Rolland, J., Condamine, F. L., Jiguet, F., and Morlon, H. (2014). Faster speciation and reduced extinction in the tropics contribute to the mammalian latitudinal diversity gradient. PLoS Biol. 12:e1001775. doi: 10.1371/journal.pbio.1001775

Rosenblum, E. B., and Harmon, L. J. (2011). "Same same but different": replicated ecological speciation in White Sands. Evolution 65, 946-960. doi: 10.1111/j.1558 5646.2010.01190.x

Ross, C. L., and Harrison, R. G. (2002). A fine-scale spatial analysis of the mosaic hybrid zone between Gryllus firmus and Gryllus pennsylvanicus. Evolution 56, 2296-2312. doi: 10.1554/0014-3820(2002)056[2296:AFSSAO]2.0.CO;2

Rossetti, D. D., de Toledo, P. M., and Goes, A. M. (2005). New geological framework for Western Amazonia (Brazil) and implications for biogeography and evolution. Quat. Res. 63, 78-89. doi: 10.1016/j.yqres.2004.10.001

Rull, V. (2008). Speciation timing and neotropical biodiversity: the TertiaryQuaternary debate in the light of molecular phylogenetic evidence. Mol. Ecol. 17, 2722-2729. doi: 10.1111/j.1365-294X.2008.03789.x

Rundle, H. D., and Nosil, P. (2005). Ecological speciation. Ecol. Lett. 8, 336-352. doi: 10.1111/j.1461-0248.2004.00715.x

Rundle, H. D., and Schluter, D. (2004). "Natural selection and ecological speciation in sticklebacks," in Adaptive Speciation, eds U. Dieckmann, M. Doebeli, J. A. J Metz, and D. Tautz (Cambridge: Cambridge University Press), 192-209.

Ruzzante, D. E., Walde, S. J., Cussac, V. E., Dalebout, M. L., Seibert, J., Ortubay, S., et al. (2006). Phylogeography of the Percichthyidae (Pisces) in Patagonia: roles of orogeny, glaciation, and volcanism. Mol. Ecol. 15, 2949-2968. doi: 10.1111/j.1365294X.2006.03010.x

Saint-Paul, U., Zuanon, J., Correa, M. A. V., Garcia, M., Fabre, N. N., Berger, U., et al. (2000). Fish communities in central Amazonian white- and blackwater floodplains. Environ. Biol. Fishes 57, 235-250. doi: 10.1023/A:1007699130333

Salisbury, C. L., Seddon, N., Cooney, C. R., and Tobias, J. A. (2012). The latitudinal gradient in dispersal constraints: ecological specialisation drives diversification in tropical birds. Ecol. Lett. 15, 845-855. doi: 10.1111/j.1461-0248.2012.01806.x

Schlick-Steiner, B. C., Seifert, B., Stauffer, C., Christian, E., Crozier, R. H., and Steiner, F. M. (2007). Without morphology cryptic species stay in taxonomic crypsis following discovery. Trends Ecol. Evol. 22, 391-392. doi: 10.1016/j.tree.2007.05.004

Schluter, D. (1988). Estimating the form of natural selection on a quantitative trait. Evolution 42, 849-861. doi: 10.2307/2408904

Schluter, D. (1996). Ecological speciation in postglacial fishes. Philos. Trans. R. Soc. Lon. B Biol. Sci. 351, 807-814. doi: 10.1098/rstb.1996.0075

Schluter, D. (2000). The Ecology of Adaptive Radiation. Oxford: Oxford University Press.

Schluter, D. (2001). Ecology and the origin of species. Trends Ecol. Evol. 16, 372-380. doi: 10.1016/S0169-5347(01)02198-X

Schluter, D., and Conte, G. L. (2009). Genetics and ecological speciation. Proc. Natl. Acad. Sci. U.S.A. 106, 9955-9962. doi: 10.1073/pnas.0901264106

Schluter, D., and Nagel, L. M. (1995). Parallel speciation by natural selection. Am. Nat. 146, 292-301. doi: 10.1086/285799

Schneider, C. J., Smith, T. B., Larison, B., and Moritz, C. (1999). A test of alternative models of diversification in tropical rainforests: Ecological gradients vs. rainforest refugia. Proc. Natl. Acad. Sci. U.S.A. 96, 13869-13873. doi: 10.1073/pnas.96.24.13869

Schoener, T. W. (2011). The newest synthesis: understanding the interplay of evolutionary and ecological dynamics. Science 331, 426-429. doi: 10.1126/science. 1193954

Schoville, S., Bonin, A., François, O., Lobreaux, S., Melodelima, C., and Manel, S. (2012). Adaptive genetic variation on the landscape: methods and cases. Annu. Rev. Ecol. Evol. Syst. 43, 23-43. doi: 10.1146/annurev-ecolsys-110411160248

Seehausen, O., Butlin, R. K., Keller, I., Wagner, C. E., Boughman, J. W., Hohenlohe, P. A., et al. (2014). Genomics and the origin of species. Nat. Rev. Genet. 15, 176-192. doi: 10.1038/nrg3644

Sexton, J. P., Hangartner, S. B., and Hoffmann, A. A. (2014). Genetic isolation by environment or distance: which pattern of gene flow is most common? Evolution 68, 1-15. doi: 10.1111/evo.12258
Shafer, A. B. A., and Wolf, J. B. W. (2013). Widespread evidence for incipient ecological speciation: a meta-analysis of isolation-by-ecology. Ecol. Lett. 16, 940-950. doi: $10.1111 /$ ele.12120

Sioli, H. (1984). The Amazon Limnology and Landscape Ecology of a Mighty Tropical River and its Basin. Dordrecht: Dr. Junk Publisher.

Sistrom, M. J., Chao, N. L., and Beheregaray, L. B. (2009). Population history of the Amazonian one-lined pencilfish based on intron DNA data. J. Zool. 278, 287-298. doi: 10.1111/j.1469-7998.2009.00576.x

Sobel, J. M., Chen, G. F., Watt, L. R., and Schemske, D. W. (2010). The biology of speciation. Evolution 64, 295-315. doi: 10.1111/j.1558-5646.2009.00877.x

Smith, B. T., McCormack, J. E., Cuervo, A. M., Hickerson, M. J., Aleixo, A., Cadena, C. D., et al. (2014). The drivers of tropical speciation. Nature 515, 406-409. doi: $10.1038 /$ nature 13687

Smith, T. B., Schneider, C. J., and Holder, K. (2001). Refugial isolation versus ecological gradients. Genetica 112, 383-398. doi: 10.1023/A:1013312 510860

Smith, T. B., Wayne, R. K., Girman, D. J., and Bruford, M. W. (1997). A role for ecotones in generating rainforest biodiversity. Science 276, 1855-1857. doi: $10.1126 /$ science. 276.5320 .1855

Templeton, A. R., Boerwinkle, E., and Sing, C. F. (1987). A cladistic-analysis of phenotypic association with haplotypes inferred from restriction endonuclease mapping. I. Basic theory and an analysis of alcohol-dehydrogenase activitiy in Drosophila. Genetics 117, 343-351.

Templeton, A. R., Crandall, K. A., and Sing, C. F. (1992). A cladistic analysis of phenotypic associations with haplotypes inferred from restriction endonuclease mapping and DNA sequence data. III. Cladogram estimation. Genetics 132, 619-633.

Travers, S. E., Smith, M. D., Bai, J., Hulbert, S. H., Leach, J. E., Schnable, P. S., et al. (2007). Ecological genomics: making the leap from model systems in the lab to native populations in the field. Front. Ecol. Environ. 5:19-24. doi: 10.1890/15409295(2007)5[19:EGMTLF]2.0.CO;2

Turner, M. G., Gardner, R. H., and O’Neill, R. V. (2001). Landscape Ecology in Theory and Practice. New York: Springer-Verlag.

Via, S. (2001). Sympatric speciation in animals: the ugly duckling grows up. Trends Ecol. Evol. 16, 381-390. doi: 10.1016/S0169-5347(01)02188-7

Via, S. (2009). Natural selection in action during speciation. Proc. Natl. Acad. Sci. U.S.A. 106, 9939-9946. doi: 10.1073/pnas.0901397106

Vines, T. H., and Schluter, D. (2006). Strong assortative mating between allopatric sticklebacks as a by-product of adaptation to different environments. Proc. Biol. Sci. 273, 911-916. doi: 10.1098/rspb.2005.3387

Wiens, J. J., and Donoghue, M. J. (2004). Historical biogeography, ecology and species richness. Trends Ecol. Evol. 19, 639-644. doi: 10.1016/j.tree.2004. 09.011

Wolf, J. B. W., Lindell, J., and Backstrom, N. (2010). Speciation genetics: current status and evolving approaches Introduction. Philos. Trans. R. Soc. B Biol. Sci. 365, 1717-1733. doi: 10.1098/rstb.2010.0023

Wright, S. (1932). "The roles of mutation, inbreeding, crossbreeding and selection in evolution," in Proceedings of the VI International Congress on Genetics (Ithaca, NY: Genetics Society of America), 1, 356-366.

Wu, C. I. (2001). The genic view of the process of speciation. J. Evol. Biol. 14, 851-865. doi: 10.1046/j.1420-9101.2001.00335.x

Conflict of Interest Statement: The authors declare that the research was conducted in the absence of any commercial or financial relationships that could be construed as a potential conflict of interest.

Received: 10 July 2014; accepted: 29 December 2014; published online: 21 January 2015.

Citation: Beheregaray LB, Cooke GM, Chao NL and Landguth EL (2015) Ecological speciation in the tropics: insights from comparative genetic studies in Amazonia. Front. Genet. 5:477. doi: 10.3389/fgene.2014.00477

This article was submitted to Evolutionary and Population Genetics, a section of the journal Frontiers in Genetics.

Copyright ( $(2015$ Beheregaray, Cooke, Chao and Landguth. This is an open-access article distributed under the terms of the Creative Commons Attribution License (CC BY). The use, distribution or reproduction in other forums is permitted, provided the original author(s) or licensor are credited and that the original publication in this journal is cited, in accordance with accepted academic practice. No use, distribution or reproduction is permitted which does not comply with these terms. 